Article

\title{
Study on Efficient Utilization Technology of Coal Pillar Based on Gob-Side Entry Driving in a Coal Mine with Great Depth and High Production
}

\author{
Xinyue Li, Nong Zhang * ${ }^{\mathbb{D}}$, Zhengzheng Xie *, Dongxu Liang and Yiming Zhao \\ Key Laboratory of Deep Coal Resource Mining, Ministry of Education of China, School of Mines, \\ China University of Mining and Technology, Xuzhou 221116, China; 1-xy@cumt.edu.cn (X.L.); \\ dongxuliang@cumt.edu.cn (D.L.); zhaoyiming@cumt.edu.cn (Y.Z.) \\ * Correspondence: zhangnong@cumt.edu.cn (N.Z.); xie_zz@cumt.edu.cn (Z.X.)
}

Received: 7 March 2019; Accepted: 18 March 2019; Published: 21 March 2019

\begin{abstract}
Improving the utilization of non-renewable resources takes a crucial position in circular economy. Gob-side entry driving technology has been widely applied in coal mines in China, such as in the Shilawusu mine (Ordos City, Inner Mongolia), here considered as a case study due to its high safety and resource-recovery rate. However, at present the complexity of coal pillar utilization makes it hard to fully master the key technology for coal pillar size design, which leads to huge waste of coal resources. Based on theoretical calculation and numerical simulation, this study analyzed the basic mechanical structure of coal pillar and the characteristics of its weakening failure, providing theoretical reference for efficient recovery of coal resources. In general, results of this study can be helpful in pursuing the efficient, hence sustainable, development of mines with Gob-side entry driving technology.
\end{abstract}

Keywords: gob-side entry driving; numerical simulation; hazardous area; stability control; efficient utilization

\section{Introduction}

Gob-side entry driving with narrow coal pillars, due to the particular stress environment and high resource recovery rate, can guarantee the roadway safety and stability on the one hand and improve the recovery of coal resources on the other. Previous researches have revealed that there exists an elastic core zone in coal pillars which can bear the overburden pressure and thus maintain the integrity of coal pillar within a certain period of time [1]. However, with the roadway heading forward, the size of the elastic core zone reduces to below its critical value. In this case, deformation, failure, and even instability of coal pillars would consequently occur. In case of coal pillar instability, normal production would be disrupted in the working face and surface subsidence would even occur, causing inestimable losses to mining staff and construction within this range [2-4]. The failure and instability of coal pillars is a gradual weakening process of coal body structure $[5,6]$. Therefore, the study of mechanical characteristics of coal pillar structure and its progressive weakening failure mechanism is highly important to the efficient recovery of coal resources and the sustainable development of coal mines.

Currently, two methods are mainly used to study coal pillar structure. One is to collect coal and rock samples on site and process them into standard parts for uniaxial or tri-axial experiments in the laboratory. The other is to conduct numerical calculation by way of all sorts of numerical simulation software. For example, Zhou et al. [7] deduced the displacement and stress distribution law of gob-side entry driving in great-depth mines by means of FLAC ${ }^{3 \mathrm{D}}$ numerical simulation and stress equilibrium equation calculation. Yang et al. [8] used AHP method to analyze the weight of influences 
of six geological factors in the process of gob-side entry driving and concluded that seam inclination was the most influential among the six factors, which provided valuable reference for gob-side entry driving design. Bai et al. [9] studied characteristics of coal pillar failure under hard roof condition and maintained that coal pillar safety and stability could be improved effectively by hydraulic fracturing roof cutting. Han et al. [10] studied the key technical parameters of roof under long-term disturbance condition and put forward the three phases of roof deformation under long-term disturbance condition by means of physical model and theoretical analysis. Zhang et al. [11,12] deduced the stress-strain relationship of a coal pillar under collaborative deformation conditions by establishing a simplified collaborative deformation mechanics model of rock stratum and coal pillar. Zhang [13] explored the failure mechanism of narrow coal pillar through field measurement and numerical calculation and concluded six failure modes of coal pillar and two phases of coal pillar deformation. Zha et al. [14] firstly analyzed the reasonable location and excavation time of gob-side entry driving with narrow coal pillars and then put forward the control technology of coal pillar stability under special geological conditions. Jiang et al. [15] established four numerical models and optimized numerical modeling for advanced geotechnical analyses (e.g., DEC, Itasca Ltd., Shanghai, China) for coal pillar yield. Yao et al. [16] studied the influence of burial depth, mining height, and advance speed of coal seam on coal pillar stability by means of Universal Distinct Element Code numerical software and put forward control measures specific to seam stability in Longhu mine. Sun et al. [17] studied the stress distribution of coal pillars with different width through theoretical analysis and FLAC ${ }^{3 \mathrm{D}}$ numerical simulation and obtained the interrelation between pillar width and mining width in the working face. Zhou et al. [3,18] explored the characteristics of stress, displacement, and fracture development in a coal pillar roof by physical experiments. Renani [19] employed two dimensional and three-dimensional finite difference analytical methods in his study and established a strengthening model of weakening cohesion and intensified friction to simulate the progressive failure of hard rock pillar. On this basis, he deduced the stress-strain curve of hard rock progressive failure mechanism. He et al. [20] used FLAC $^{3 \mathrm{D}}$ numerical simulation software to analyze the risk indicator distribution of coal pillars under different aspect ratios and complex pressure; besides, the tendentious characteristics of coal pillar failure were studied as well. Zheng et al. [21,22] studied the distribution law of stress field in the whole mining process of gob-side entry driving with different entry protection coal pillars. Zhao et al. [23] analyzed the overlying strata structure and stability characteristics of roadway surrounding rock structure and established a mechanical model of surrounding rock structure in the case of gob-side entry driving which revealed the mechanism of surrounding rock deformation control in a fully mechanized roadway. Kumar et al. [24] conducted a field research of mines which employed long-wall mining method in Czech Republic and evaluated the coal pillar stability through CMRI formula and numerical simulation of strain softening. Mathey et al. [25] studied the computational formula of coal pillar strength in South Africa through empirical formula and numerical simulation and concluded that when the aspect ratio exceeds the critical value by five times, coal pillar strength would increase by exponential growth. $\mathrm{Xi}$ et al. [26] used field measurement and numerical simulation to determine the coal pillar width.

Most of the above-mentioned researches place their focus on the stress distribution of coal pillar structure. Comparatively speaking, quite rare efforts have been made to explore the mechanical structures, mechanical properties, and progressive failure mechanisms. Here, FLAC3D was used to simulate the excavation process. In total, eight groups of model calculation were designed and conducted, the excavation distance being $30 \mathrm{~m}, 35 \mathrm{~m}, 40 \mathrm{~m}, 45 \mathrm{~m}, 50 \mathrm{~m}, 55 \mathrm{~m}, 60 \mathrm{~m}$, and $70 \mathrm{~m}$ respectively. Then the progressive weakening failure mechanism of coal pillars was studied according to field stress monitoring and peephole images of coal pillar side. A whole set of efficient utilization technology for coal pillar were formed accordingly. 


\section{Stress State Analysis of Coal Pillar Structure}

\subsection{Main Roof Fracture Line Location}

To analyze the stress state of narrow coal pillar structures in the process of gob-side entry driving, the primary concern falls upon the interaction between the structural blocks of overlying key strata, the supporting force of caving gangue in the gob, the supporting force of rise side and coal pillar, and the weight of overlying strata, which are shown in Figure 1. Judging from whether key blocks can form hinge structures in overlying strata, the stress structure above a coal pillar can be divided into two types. One is the twisting force exerted upon coal pillar structure due to the slide and deflection of roof key strata, as is shown in Figure 1a; the other refers to the vertical stress exerted upon coal pillar structures by overlying key strata, because roof key strata cannot form corresponding working structures, as shown in Figure $1 \mathrm{~b}$. Therefore, the location of a fracture structure in the overlying strata above the narrow-coal-pillar roadway driving along gob is an essential prerequisite for the study of stress transmission in coal pillar structure.

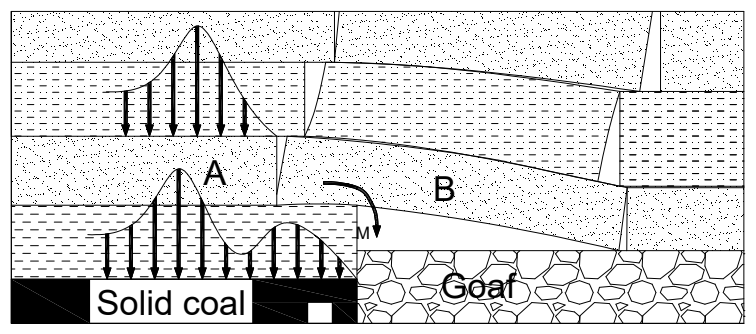

(a)

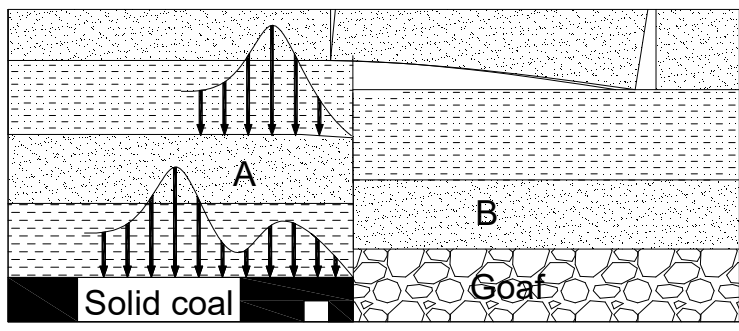

(b)

Figure 1. Sketch of typical stope structure with narrow coal pillars. (a) model 1; (b) model 2.

Under the impact of the first weighting, the main roof over the small-coal-pillar roadway driving along the gob experiences an "O- $\mathrm{X}$ " fracture which develops into a voussoir beam structure along the gob due to periodic weighting. The force transmitted to the coal pillar structure is mainly controlled by the hinge structure which is formed by key blocks after the fracture occurs. Generally speaking, the fracture line of main roof is mainly located in the following four positions: outside the coal pillar, above the coal pillar, above the roadway, or inside the solid coal side. There is also another situation: there is no hinge structure formed in the main roof above coal pillar. The stress state of coal pillar varies in accordance with the hinge structures formed by the fracture lines of different locations.

According to the maximum bending moment theory [27], the following assumptions can be made: (1) Both the upper and lower strata of main roof belong to elastic beam structure; (2) The main roof is a rigid body; and (3) The starting point of clamping is a fixed support which does not displace or deflect. The original starting point of clamping is taken from the stress zone of primary rock. The stress boundary of bedrock at the solid coal side (denoted as $\mathrm{L}_{1}$ ) is usually twice the distance between abutment pressure peak value and the integrated coal beside the roadway (denoted as $\mathrm{x}_{1}$ ). Therefore, $\mathrm{L}_{1}=2 \mathrm{x}_{1}$. The neighboring Hulusu mine which has similar geological conditions provides practical reference for this study. According to the data from Hulusu mine, $x_{1}=7.5 \mathrm{~m}$, then $\mathrm{L}_{1}=15 \mathrm{~m}$ [28].

The immediate roof which contacts the main roof directly and upper strata can be taken as a linear elastic medium. The location of fracture line can be deduced according to the location of maximum moment before the fracture of main roof. To be specific, the classical $\mathrm{M}_{\max }$ formula can be used in this case $[27,29]$.

$$
\mathrm{M}_{\max }=\mathrm{M}_{0} \mathrm{e}^{-\alpha \chi}\left[\cos \beta \chi+\frac{\alpha(\mathrm{r}+\mathrm{s})+\mathrm{rQ}_{0} / \mathrm{M}_{0}}{\beta(\mathrm{r}-\mathrm{s})} \sin \beta \chi\right]
$$

where: $\mathrm{r}=\sqrt{\mathrm{k} /(\mathrm{EI})}, \mathrm{s}=\mathrm{N} /(\mathrm{EI}), \alpha=\sqrt{(\mathrm{r} / 2-\mathrm{s} / 4)}, \beta=\sqrt{(\mathrm{r} / 2+\mathrm{s} / 4)}, \mathrm{M}_{0}=\left(\mathrm{R}_{\mathrm{S}}+\mathrm{N} / \mathrm{bh}\right) \cdot \mathrm{bh}^{2} / 6$, $\mathrm{I}=\mathrm{bh}^{3} / 12, \mathrm{Q}^{\prime}=\mathrm{L}(\mathrm{h} \gamma+\mathrm{q}), \mathrm{N}^{\prime}=\frac{\mathrm{LQ}^{\prime}}{2(\mathrm{~h}-\Delta \mathrm{S})}, \mathrm{Q}_{0}=\mathrm{qL}+\mathrm{Q}^{\prime}-\mathrm{F}$. 
In the above formula, $\mathrm{M}_{0}, \mathrm{Q}_{0}$ and $\mathrm{N}$ denote beam section internal forces at the starting point before the fracture of main roof $(\mathrm{kN})$; $E$ refers to elasticity modulus of main roof $(\mathrm{MPa})$; $\mathrm{R}_{\mathrm{s}}$ denotes tensile strength of main roof $(\mathrm{MPa})$; h denotes thickness of main roof $(\mathrm{m})$; $b$ refers to width of main roof whose unit width is $1 \mathrm{~m}$; Symbols as in the List on page $1(\mathrm{~L}=22)$.

Shilawusu mine is located in Inner Mongolia Autonomous Region of China. With an average buried depth of $700 \mathrm{~m}$, its coal seam whose Protodyakonov coefficient (f) is around 1.79, which is soft and medium hard coal [30]. The basic geological parameters of $221_{\mathrm{up}} 01$ gob-side entry in Shilawusu mine are as follows: $\mathrm{h}=4.99 \mathrm{~m}, \gamma=25 \mathrm{kN} / \mathrm{m}^{3}, \mathrm{E}=9.7 \mathrm{GPa}$, and $\mathrm{R}_{\mathrm{s}}=3.9 \mathrm{MPa}$. Suppose that the fracture length of rock $B$ is equal to the length of fractured rock $A$, and then $\Delta S=h / 6=0.832 \mathrm{~m}$. By calculation the following can be obtained: $\mathrm{I}=10.4 \mathrm{~m}^{3}, \mathrm{r}=0.044 / \mathrm{m}^{2}, \mathrm{~N}=20.049 \mathrm{MN}, \mathrm{Q}^{\prime}=25.325 \mathrm{MN}$, $\mathrm{S}=1.967 \times 10^{-4} \mathrm{~m}^{2}, \alpha=0.1481 \mathrm{~m}, \beta=0.06457 / \mathrm{m}, \mathrm{M}_{0}=16.69 \mathrm{MN}$. In terms of cushion coefficient $\mathrm{k}$, the cushion coefficient of Baodian mine $(\mathrm{k}=200 \mathrm{MPa})$ is used in this study in that the burial depth of the two mines is similar [17]. Through calculation and origin data processing, $\mathrm{M}_{\max }-\mathrm{x}$ curve is obtained, as is shown in Figure 2, where $\mathrm{x}$ denotes the distance between the starting point of clamping and maximum bending moment.

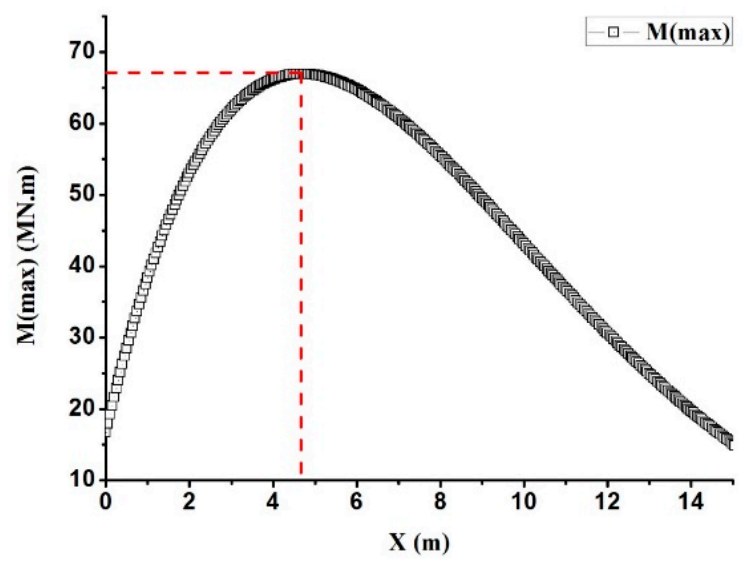

Figure 2. Trend chart of main roof bending moment variation.

Through $\mathrm{M}_{\max }$ formula and data and image processing, the maximum value of $\mathrm{M}_{\max }$ can be obtained when $\mathrm{x}=4.7 \mathrm{~m}$. In other words, this is the limit value of $\mathrm{M}_{\max }$ 's first derivative. Accordingly, it can be concluded that the distance between fracture line and clamping point is $4.7 \mathrm{~m}$. Then the distance from fracture line to solid coal side can be determined by the equation $\mathrm{x}_{0}=\mathrm{L}_{1}-\mathrm{x}$. To be specific, the fracture line is located inside the solid coal side at the distance of $10.3 \mathrm{~m}\left(\mathrm{x}_{0}=10.3 \mathrm{~m}\right)$.

\subsection{The Analysis of Coal Pillar Structure Mechanical Model}

According to the characteristics of overlying strata fracture and displacement, the fracture line is confirmed to locate inside the solid coal side, which conforms to the fourth situation as introduced above. Therefore, the mechanical model of coal pillar structure can be established through simplifying the stress structure model of coal pillar. In accordance with the actual size of coal pillar measured in the field, the model is simplified into a cylinder structure with a rectangular cross-section, as is shown in Figure 3.

According to the stress state analysis of the coal pillar, segment $A B$ is the internal stress field of overlying strata. Since the damage degree of coal pillar surface is relatively high, the effect of force transmission is almost zero. Consequently, the regional stress transmission in the internal stress field is higher in the middle section than at both sides. The stress transmitted from the roof is the regional stress $F_{Y}$ which is vertically downward. Segment $C D$ bears the supporting force $F_{Z}$ from the floor which is opposite to the regional stress on segment $A B$. Segment AD denotes the cylindrical surface adjacent to the solid coal side. The stress exerted upon this segment is mainly the anchoring force $\mathrm{F}_{\mathrm{G}}$ and the friction of coal pillar. Since anchoring force is influenced by anchorage quality and the 
distance between anchorage point and the roof/floor, $\mathrm{F}_{\mathrm{G}}$ is a heterogeneous regional stress. Segment $\mathrm{BC}$ denotes the cylindrical surface adjacent to the goaf and the stress exerted upon it is mainly the friction $\mathrm{F}_{\mathrm{M}} . \mathrm{M}$ is the clockwise twisting force transmitted to coal pillar structure due to the rotation of overlying strata fractured blocks. In the structure model, the force exerted upon segments $\mathrm{AB}, \mathrm{BC}$, $\mathrm{CD}$, and $\mathrm{AD}$ are all regional stress. To simplify the calculation, the regional stress is converted to concentrated force, as is shown in Figure 4.

The analysis of simplified structural model indicates that it is possible for the model to be in an apparent steady state. To be specific, the cylinder structure experiences a series of minor form changes. The elastic mechanical equation of coal pillar can be shown as follows:

$$
\left\{\begin{array} { l } 
{ \sum \mathrm { M } = \mathrm { c } _ { 1 } \mathrm { a } } \\
{ \sum \mathrm { F } _ { \mathrm { X } } = \mathrm { c } _ { 2 } \mathrm { a } } \\
{ \sum \mathrm { F } _ { \mathrm { Y } } = \mathrm { c } _ { 3 } \mathrm { a } }
\end{array} \stackrel { \text { Approximate } } { \longrightarrow } \left\{\begin{array}{l}
\sum \mathrm{M}=\lim _{\mathrm{c}_{1} \rightarrow 0} \mathrm{c}_{1} \\
\sum \mathrm{F}_{\mathrm{X}}=\lim _{\mathrm{c}_{2} \rightarrow 0} \mathrm{c}_{2} \\
\sum \mathrm{F}_{\mathrm{Y}}=\lim _{\mathrm{c}_{3} \rightarrow 0} \mathrm{c}_{3}
\end{array}\right.\right.
$$

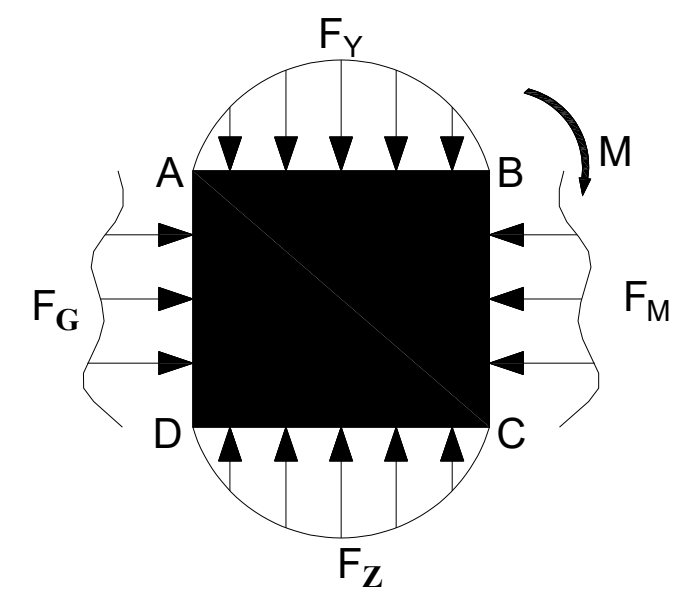

Figure 3. The mechanical model of coal pillar structure.

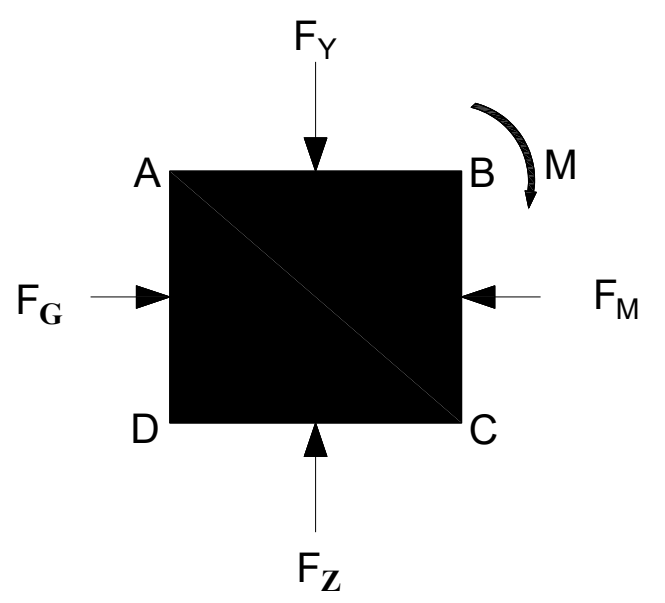

Figure 4. The simplified model of concentrated force on coal pillar structure.

The composite action of forces exerted upon coal pillar structure leads coal pillar into an apparent steady state. The sum of moments $\Sigma \mathrm{M}$ exerts on the rotation of coal pillar structure. $\mathrm{c}_{1}$ denotes the relevant rotation coefficients of coal pillar structure, such as aspect ratio, the development state of internal fracture. External force $\sum \mathrm{F}_{X}$ and $\sum \mathrm{F}_{Y}$ exert on coal pillar structure horizontally and vertically respectively. $c_{2}$ and $c_{3}$ denote horizontal and vertical deviation coefficient of coal pillar structure respectively. $\Sigma \mathrm{M}$ is simplified through horizontal force and vertical force and the simplified mechanical model of coal pillar is shown in Figure 5. 


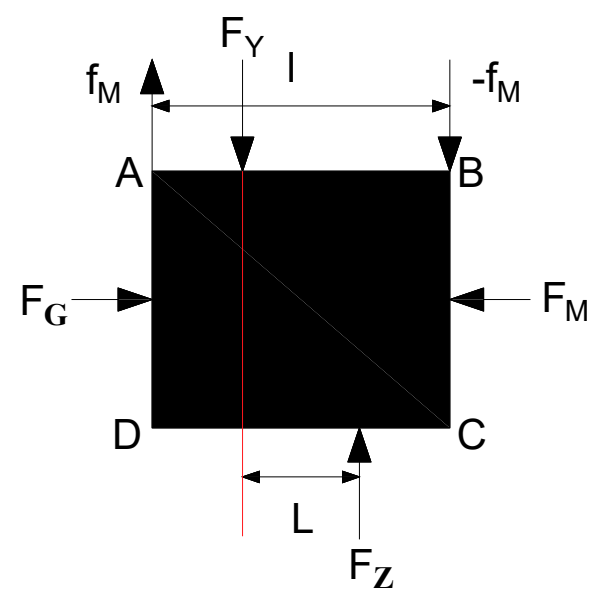

Figure 5. Sketch map of moment replacement of coal pillar structure.

Based on the analysis of the simplified model, the stress equilibrium equation of the interface can be shown as follows:

$$
\left\{\begin{array}{c}
\mathrm{f}_{\mathrm{M}} \times 1=\mathrm{M} \\
\mathrm{F}_{\mathrm{Y}} \times \mathrm{L}=\mathrm{M}
\end{array} \rightarrow \mathrm{f}_{\mathrm{M}} \times 1=\mathrm{F}_{\mathrm{Y}} \times \mathrm{L}\right.
$$

In terms of the interaction of integrated forces, $\mathrm{f}_{\mathrm{M}}$ and $\mathrm{F}_{Y}$ can be seen as a group of shear force and $-f_{M}$ and $F_{Z}$ can be taken as another group. Within the small range of $L$, one group of shear force exerts upon the stress boundary of coal pillar structure and the heterogeneous stress of overlying strata is transmitted from the side closer to the gob deep into the solid coal side. Therefore, the shear action of integrated forces shifts toward the gob-side accordingly. The magnitude of the force is related with the fracture length in the overlying strata and the development of fractures inside coal pillar structure. Under the impact of shear force, displacement occurs correspondingly toward the opposite direction inside the coal pillar structure, which is shown in Figure 6. As shown, there are two groups of displacement inside coal pillar structure which are opposite to each other. In the plane vertical to the coal pillar axis, there exists a curve composed of control points of opposite displacement. On the two sides of the curve exists two groups of displacement which are opposite in direction. Therefore, this curve can be defined as "critical line of instability" of coal pillar structure.

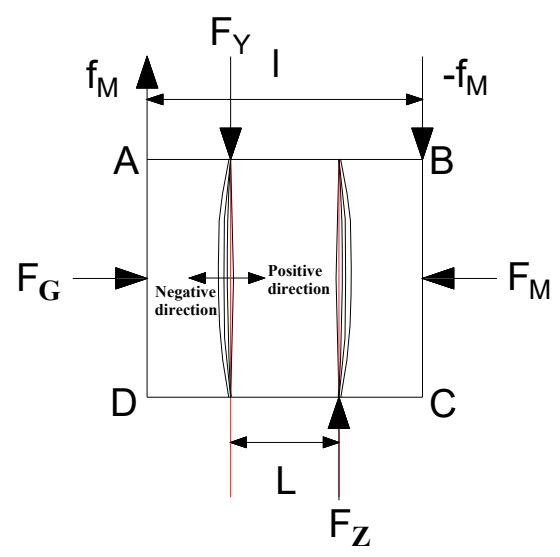

Figure 6. Diagram of displacement inside coal pillar structure.

\section{The Failure Law Analysis of Coal Pillar Structure}

\subsection{Setting Up the Numerical Model}

According to the geological conditions of Shilawusu mine and its roadway characteristics, a numerical calculation model was established by using finite difference software FLAC ${ }^{3 \mathrm{D}}$. Through 
simulating the gob-side entry driving process of $30 \mathrm{~m}, 35 \mathrm{~m}, 40 \mathrm{~m}, 45 \mathrm{~m}, 50 \mathrm{~m}, 55 \mathrm{~m}, 60 \mathrm{~m}$, and $70 \mathrm{~m}$ respectively, the horizontal and vertical displacement was measured when coal pillar was in a stable state. Meanwhile, the distribution of vertical stress above coal pillar was also measured as the criterion to judge the dangerousness of coal pillar structure. As can be seen from the Figure 7, the height of coal seam is $5.0 \mathrm{~m}$, and the roof is composed of medium-fine sandstone and the floor sandy mudstone.

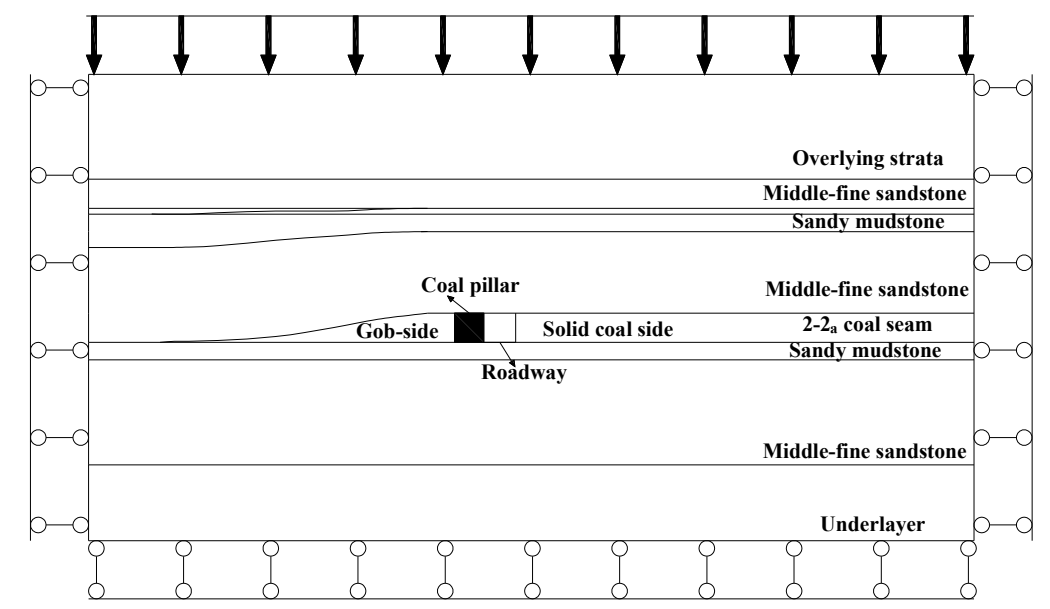

Figure 7. Model of gob-side entry driving.

According to the geological parameters of the mine, the overlying strata were simplified appropriately to establish FLAC ${ }^{3 \mathrm{D}}$ numerical calculation model. Then the stability state of coal pillar was analyzed respectively when gob-side entry driving advanced to $30 \mathrm{~m}, 35 \mathrm{~m}, 40 \mathrm{~m}, 45 \mathrm{~m}$, $50 \mathrm{~m}, 55 \mathrm{~m}, 60 \mathrm{~m}$, and $70 \mathrm{~m}$ in the roadway.

\subsection{Stress Characteristics of Coal Pillar in the Excavation Process of Gob-Side Entry Driving}

Corresponding to the excavation state when gob-side entry driving advanced to $30 \mathrm{~m}, 35 \mathrm{~m}, 40 \mathrm{~m}$, $45 \mathrm{~m}, 50 \mathrm{~m}, 55 \mathrm{~m}, 60 \mathrm{~m}$, and $70 \mathrm{~m}$ in the roadway, eight calculation models were established to record the stress state of coal pillar in the process of excavation. The three-dimensional stress structure models are shown in Figure 8.

As is shown in the above diagrams, there are three stress concentration areas: (1) head-on stress disturbance area which is denoted as $\mathrm{a}_{1}, \mathrm{~b}_{1}, \mathrm{c}_{1}, \mathrm{~d}_{1}, \mathrm{e}_{1}, \mathrm{f}_{1}, \mathrm{~g}_{1}$, and $\mathrm{h}_{1}$ respectively; (2) solid coal side stress distribution area which is denoted as $\mathrm{a}_{2}, \mathrm{~b}_{2}, \mathrm{c}_{2}, \mathrm{~d}_{2}, \mathrm{e}_{2}, \mathrm{f}_{2}, \mathrm{~g}_{2}$, and $\mathrm{h}_{2}$ respectively; (3) coal pillar structure stress distribution area whose stress core area is denoted as $\mathrm{a}_{0}, \mathrm{~b}_{0}, \mathrm{c}_{0}, \mathrm{~d}_{0}, \mathrm{e}_{0}, \mathrm{f}_{0}, \mathrm{~g}_{0}$, and $\mathrm{h}_{0}$ respectively. According to the analysis of Figure 8 , in the process of gob-side entry driving, the stress peak value of head-on stress disturbance area is constantly the largest while that of coal pillar structure stress distribution area is the smallest.

The characteristics of coal pillar structure stress distribution indicate that the stress distributed in the marginal area of coal pillar structure is close to zero while peak load appears in the central area. This is in line with the argument that the load bearing on the damaged surface is nearly zero and there is an "elastic core zone" inside the coal pillar. However, the stress distribution of stress core area inside the coal pillar structure displays a trend of steady growth and drastic decline. The discontinuity point of peak value in stress core area is located close to the roadway, and the starting point of stress core area is close to the gob-side. From the starting point to the discontinuity point, the stress grows steadily; but it falls dramatically after the discontinuity point. In addition, the stress core area is located close to the roadway side as a whole. 


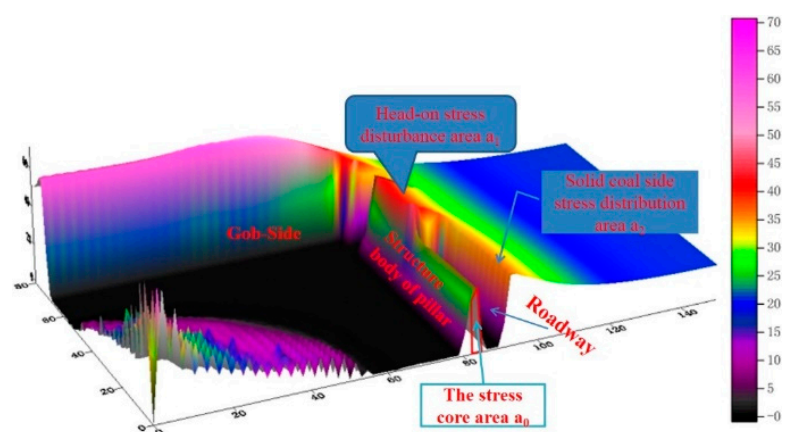

(a)

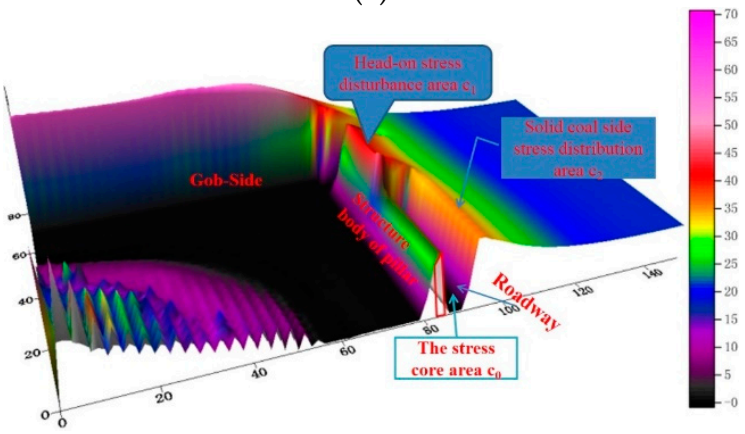

(c)

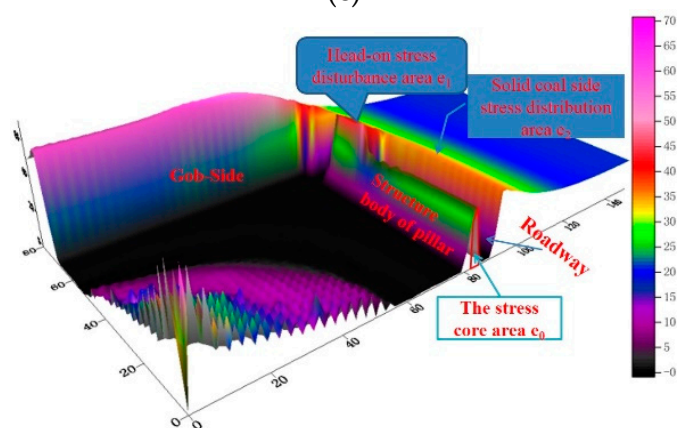

(e)

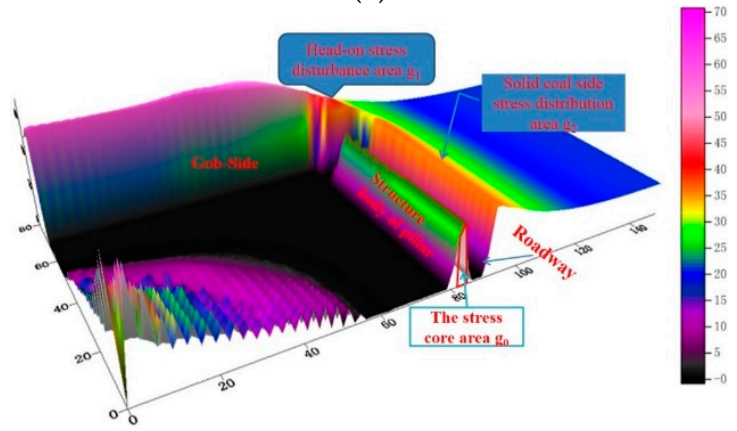

(g)

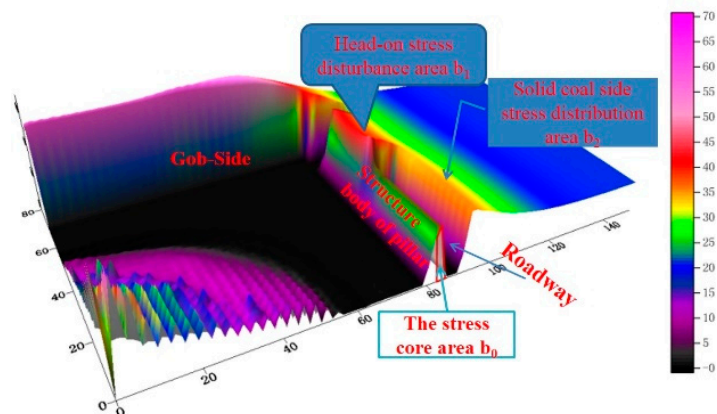

(b)

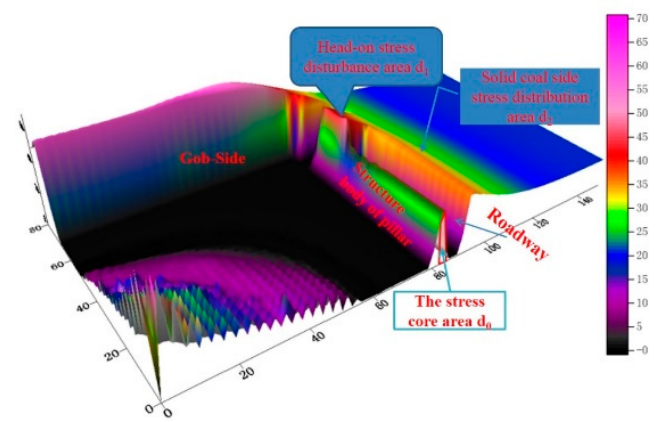

(d)

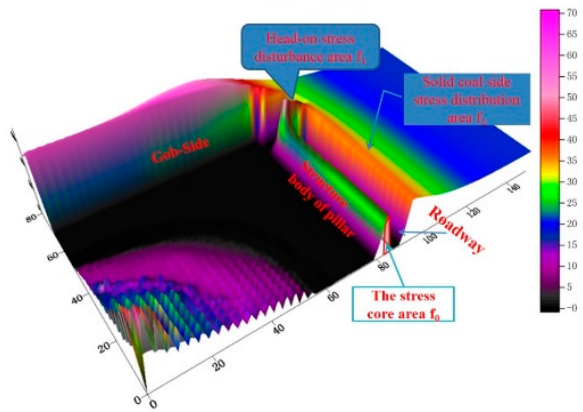

(f)

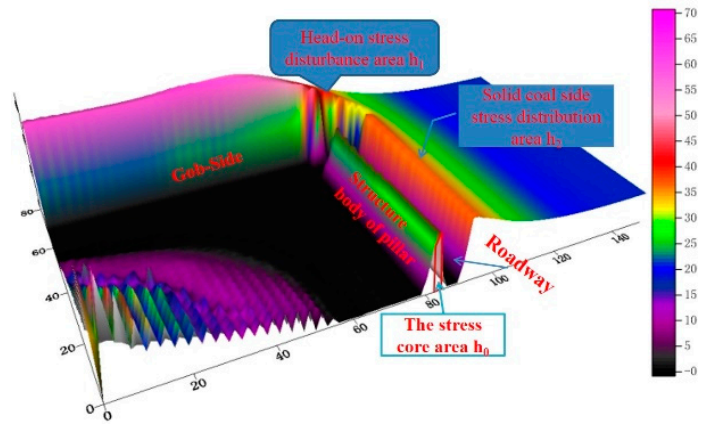

(h)

Figure 8. 3D diagram of stress distribution characteristics of gob-side entry driving. (a) Characteristic diagram of spatial stress distribution at the driving distance of $30 \mathrm{~m}$; (b) Characteristic diagram of spatial stress distribution at the driving distance of $35 \mathrm{~m}$; (c) Characteristic diagram of spatial stress distribution at the driving distance of $40 \mathrm{~m}$; (d) Characteristic diagram of spatial stress distribution at the driving distance of $45 \mathrm{~m}$; (e) Characteristic diagram of spatial stress distribution at the driving distance of $50 \mathrm{~m}$; (f) Characteristic diagram of spatial stress distribution at the driving distance of $55 \mathrm{~m}$; (g) Characteristic diagram of spatial stress distribution at the driving distance of $60 \mathrm{~m}$; (h) Characteristic diagram of spatial stress distribution at the driving distance of $70 \mathrm{~m}$. 
As the distance between head-on and open-off cut decreases, the stress distribution of coal pillar structure varies from the original smooth state along the axis to a tooth-like state. As the driving distance is over $40 \mathrm{~m}$ (the distance between head-on and open-off cut is $20 \mathrm{~m}$ ), the stress distribution of coal pillar structure appears to be tooth-like. Accordingly, it can be deduced that the change of geological condition in front of the driving end does exert certain impact on the stress distribution of coal pillar structure. According to the actual field investigation, the surrounding rock in front of the driving end is greatly influenced by the disturbance of mechanical excavation and asymmetric engineering operations. Therefore, it can be inferred that the stress distribution of coal pillar structure in the working face tends to be tooth-like.

\subsection{Distribution Characteristics and Law of Dangerous Zones}

According to previous studies and theories on the failure of coal pillar structure, there are two modes of failures: tensile failure and compression and shear failure [31]. Quite rare efforts have ever been made on the statistics of dangerous zones caused by the failure of coal pillar structure. To fill this gap, by means of FLAC ${ }^{3 \mathrm{D}}$ numerical calculation model established above, the displacement trend inside coal pillar structure was recorded when gob-side entry driving advanced to $30 \mathrm{~m}, 35 \mathrm{~m}, 40 \mathrm{~m}$, $45 \mathrm{~m}, 50 \mathrm{~m}, 55 \mathrm{~m}, 60 \mathrm{~m}$, and $70 \mathrm{~m}$ in the roadway. Through comparison and analysis of displacement direction and amount, the danger interface of coal pillar structure in the process of roadway driving was determined. The relationship between X-displacement (horizontal displacement) and roadway is shown in Figure 9.

In the process of driving roadway along the gob from $30 \mathrm{~m}$ to $35 \mathrm{~m}, 40 \mathrm{~m}, 45 \mathrm{~m}, 50 \mathrm{~m}, 55 \mathrm{~m}, 60 \mathrm{~m}$, to $70 \mathrm{~m}$ in the end, one measuring line was set every $0.5 \mathrm{~m}$ along X-displacement of coal pillar structure. All the measuring lines constituted the trend diagram of X-displacement of coal pillar structure. As it is shown in Figure 9, displacement boundary marks off the area where X-displacement is zero. The displacement above the displacement boundary is set as positive which directs towards the roadway; the displacement below the boundary is set as negative which directs towards the gob. On both sides of displacement change line, displacement direction deflects at some points in coal pillar structure. Point A denotes the first point where displacement direction deflects; $C D$ represents the roadway width.

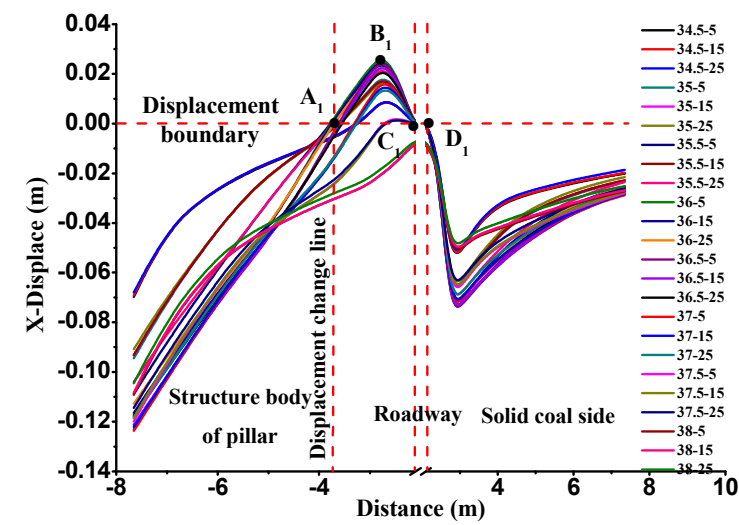

(a)

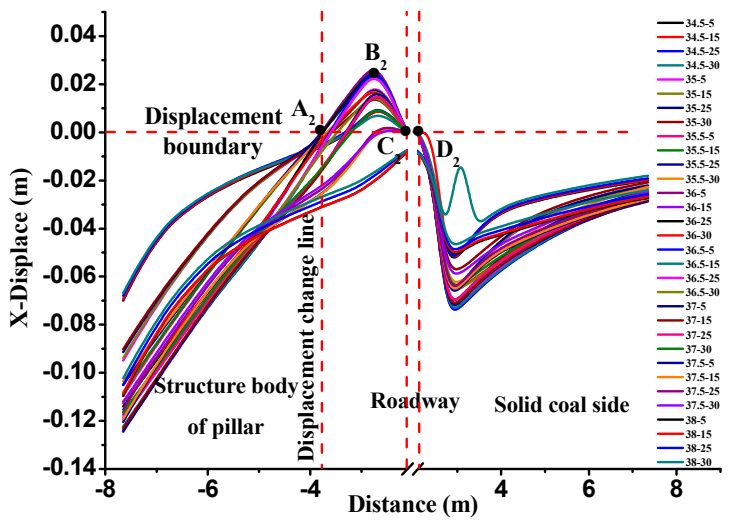

(b)

Figure 9. Cont. 


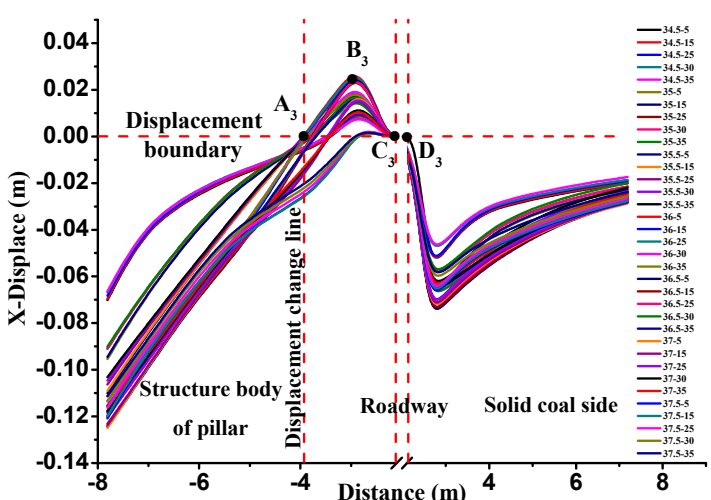

(c)

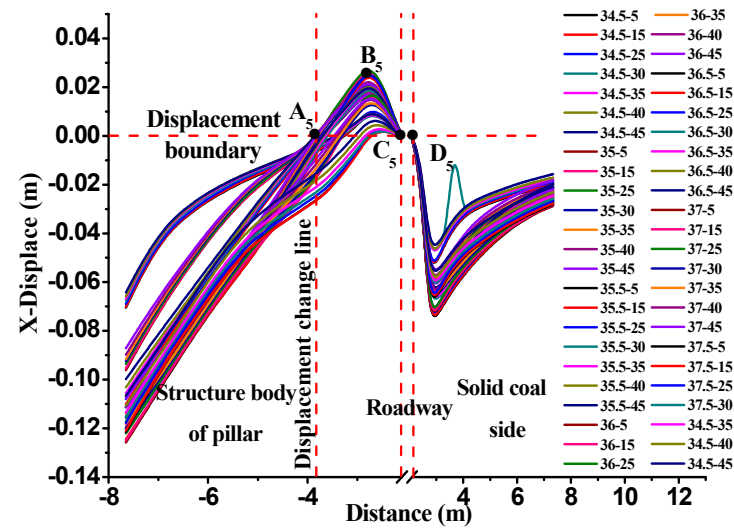

(e)

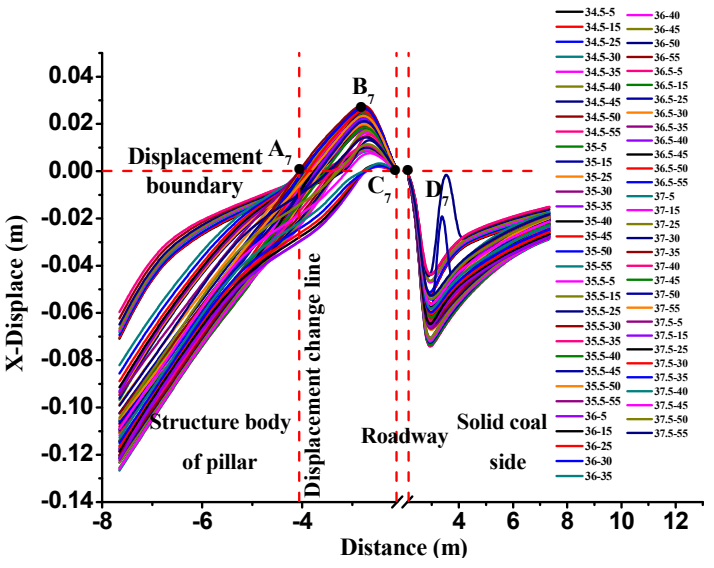

(g)

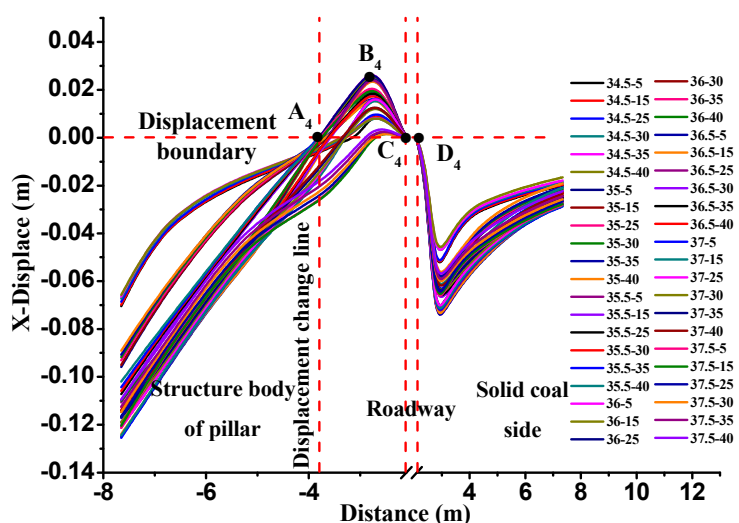

(d)

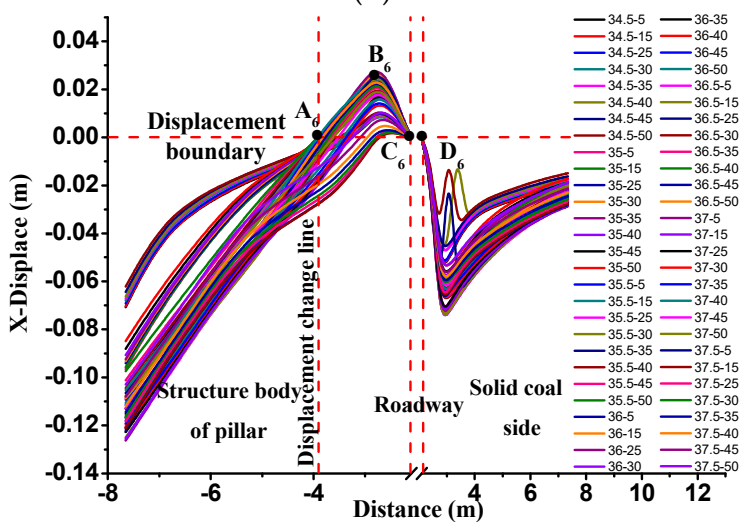

(f)

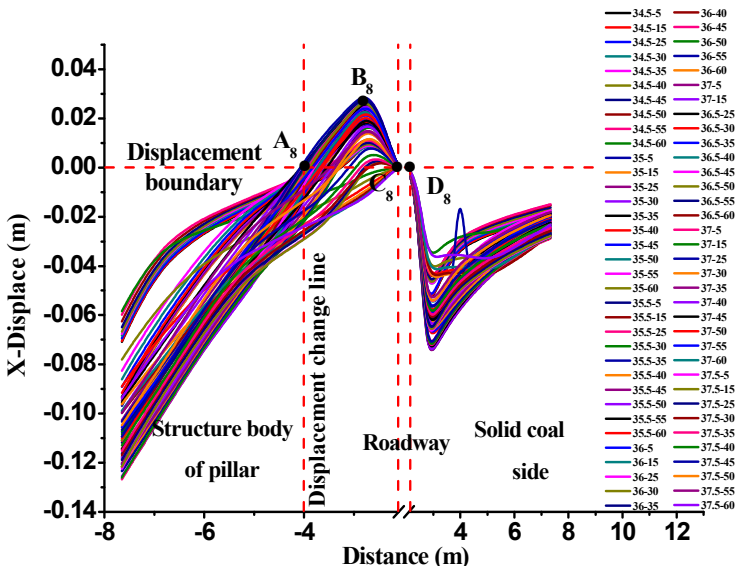

(h)

Figure 9. Diagram of the relationship between X-displacement of coal pillar structure and the roadway. (a) The relationship between $\mathrm{X}$-displacement and the roadway at the driving distance of $30 \mathrm{~m}$; (b) The relationship between X-displacement and the roadway at the driving distance of $35 \mathrm{~m}$; (c) The relationship between X-displacement and the roadway at the driving distance of $40 \mathrm{~m}$; (d) The relationship between X-displacement and the roadway at the driving distance of $45 \mathrm{~m}$; (e) The relationship between X-displacement and the roadway at the driving distance of $50 \mathrm{~m}$; (f) The relationship between X-displacement and the roadway at the driving distance of 55 $\mathrm{m}$; (g) The relationship between X-displacement and the roadway at the driving distance of $60 \mathrm{~m}$; (h) The relationship between $\mathrm{X}$-displacement and the roadway at the driving distance of $70 \mathrm{~m}$.

In the above diagram, the position of Point $\mathrm{A}$ is closely related with the position of displacement change line. Through comparison it is discovered that displacement change line appears within the range of 1.4-2 $\mathrm{m}$ inside the coal pillar structure. According to the statistics of roadway driving from 
$30 \mathrm{~m}$ to $70 \mathrm{~m}$, the displacement change lags behind the head-on by $5-10 \mathrm{~m}$ which is approximately equal to two working days' driving time in the Shilawusu mine. The control points of X-displacement deflection from the floor to the roof do not exist in the same vertical plane. According to the statistics of X-displacement data, the control points of X-displacement deflection form a concave surface in coal pillar structure. In other words, there exists a concave curve in the plane vertical to coal pillar axis. This curve is thus defined as "instability critical line" of coal pillar structure, as is shown in Figure 10.

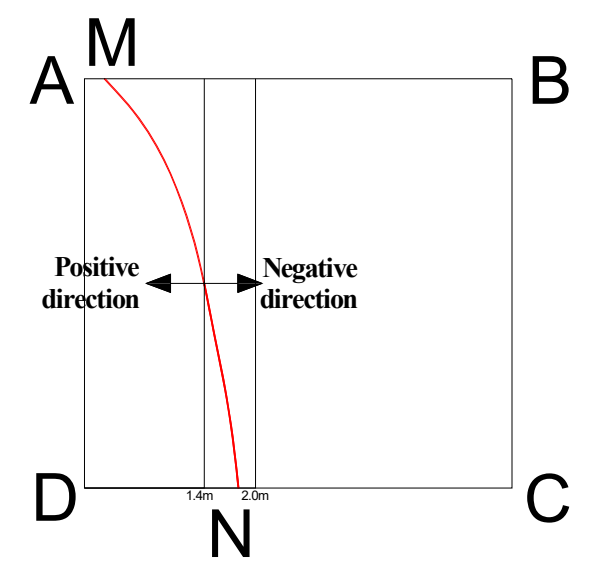

Figure 10. Sketch map of the "instability critical line" of a coal pillar structure.

As it is shown in Figure 10, the red line marks the interface where displacement occurs in opposite directions inside coal pillar structure. The displacement near the roof is more inclined to the roadway and that near the floor is confined within the range of 1.4-2.0 $\mathrm{m}$ inside coal pillar structure. The red line $\mathrm{MN}$ forms a surface structure which exerts horizontal tensile action on coal pillar structure. Moreover, the displacements on both sides of the red interface are asymmetric tensile displacements in opposite directions. In terms of the poor tensile resistance of rock mass structure, it can be deduced that tensile failure is more likely to occur on the surface marked by the red line. In other words, this area is the dangerous zone of tensile failure. Accordingly, it can be concluded that there exists a dangerous zone composed of tensile failure control points within the range of two meters close to the roadway side. This verifies the existence of "instability critical line" as stated above reversely. The statistical analysis of X-displacement reveals the distribution characteristics of dangerous zones of tensile failure inside coal pillar structure. The following Figure 11 shows the data of vertical displacement (Z-displacement) distribution inside coal pillar structure.

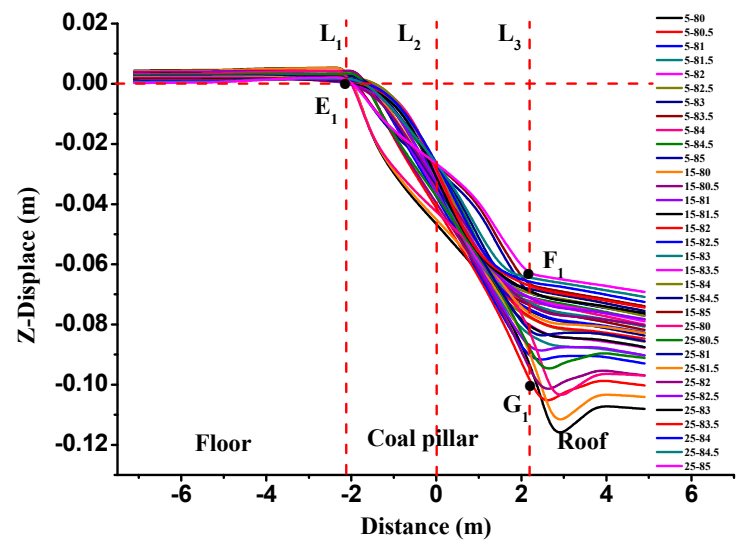

(a)

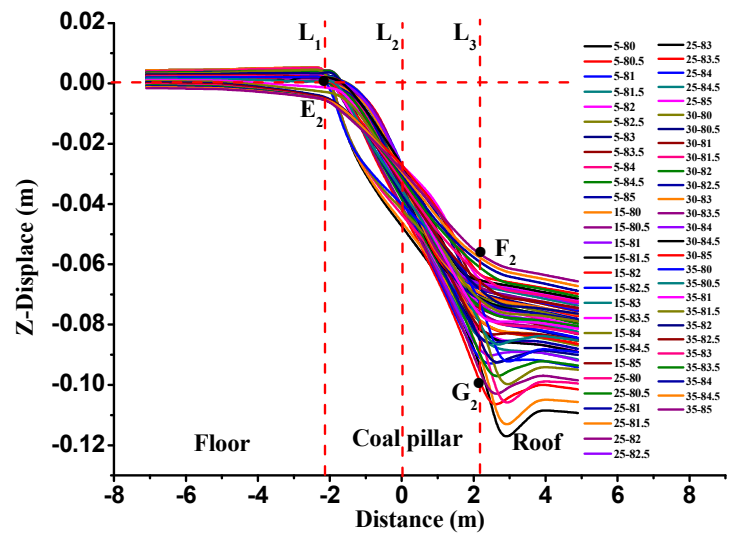

(b)

Figure 11. Cont. 


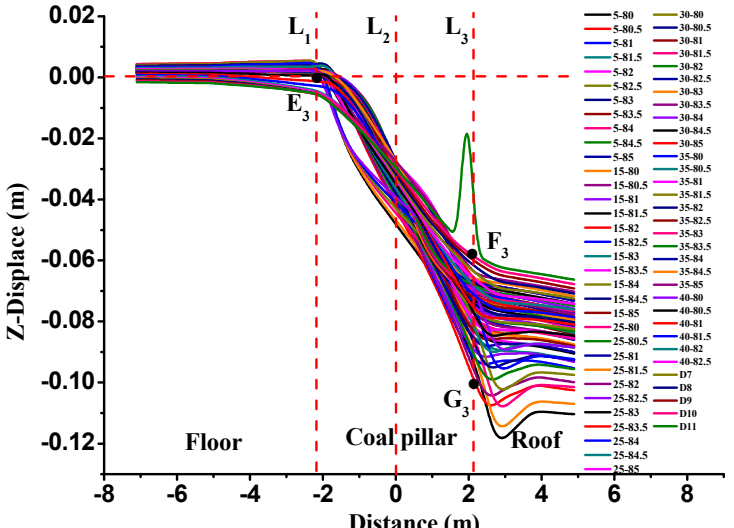

(c)

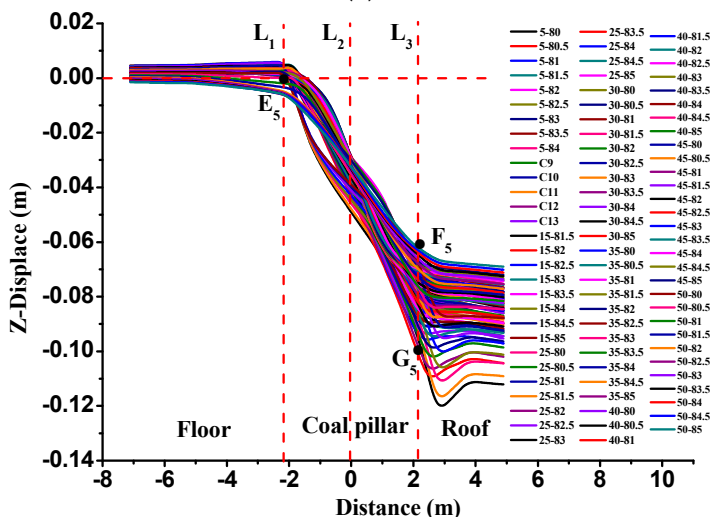

(e)

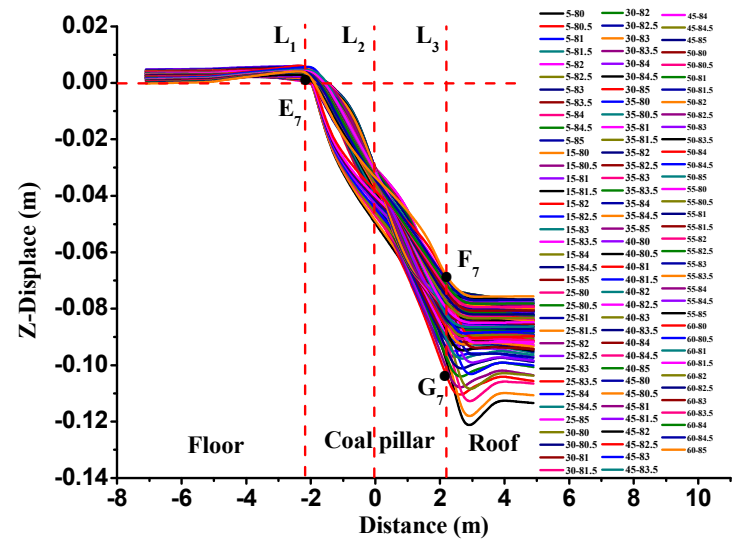

(g)

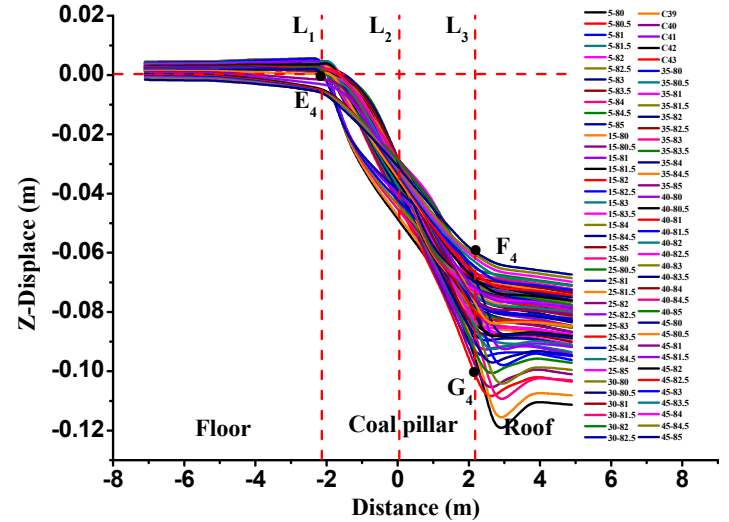

(d)

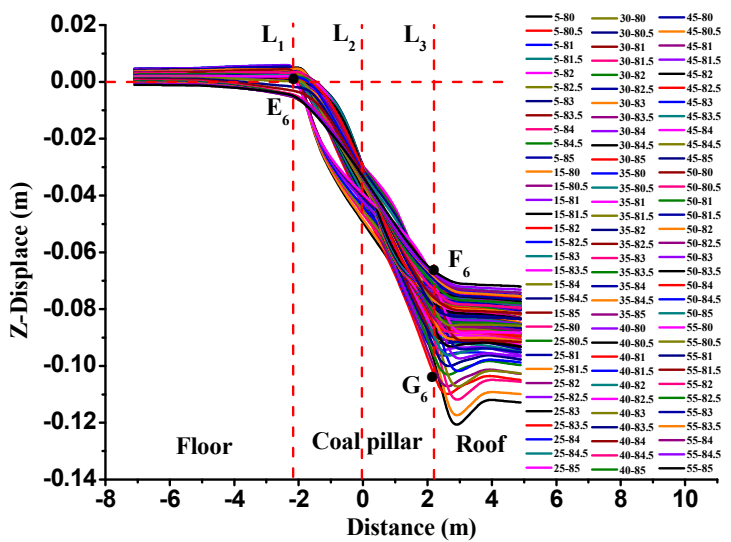

(f)

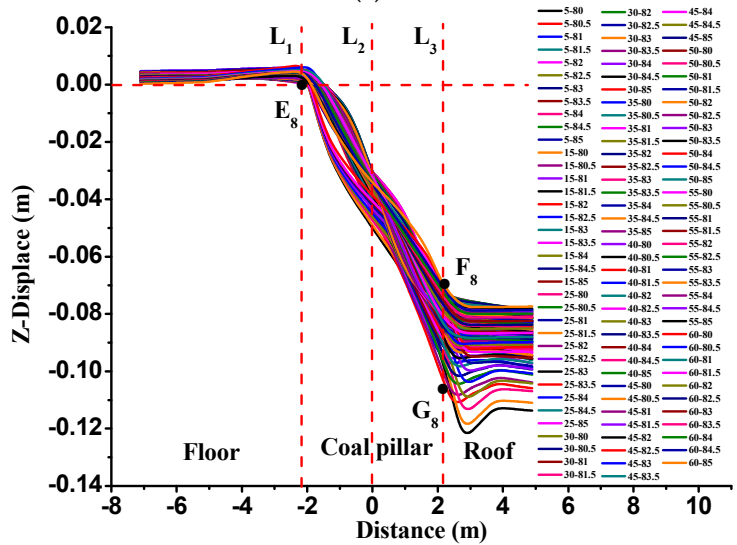

(h)

Figure 11. Diagram of the relationship between Z-displacement of coal pillar structure and the roadway. (a) The relationship between $Z$-displacement and the roadway at the driving distance of $30 \mathrm{~m}$; (b) The relationship between Z-displacement and the roadway at the driving distance of $35 \mathrm{~m}$; (c) The relationship between Z-displacement and the roadway at the driving distance of $40 \mathrm{~m}$; (d) The relationship between Z-displacement and the roadway at the driving distance of $45 \mathrm{~m}$; (e) The relationship between Z-displacement and the roadway at the driving distance of $50 \mathrm{~m}$; (f) The relationship between Z-displacement and the roadway at the driving distance of $55 \mathrm{~m}$; (g) The relationship between Z-displacement and the roadway at the driving distance of $60 \mathrm{~m}$; (h) The relationship between $Z$-displacement and the roadway at the driving distance of $70 \mathrm{~m}$.

The diagram is composed of three parts: the first part refers to the area ranging from floor surface downward to $5 \mathrm{~m}$ depth; the second part is coal pillar structure; and the third part refers to the area ranging from roof surface upward to $2.8 \mathrm{~m}$ depth. $\mathrm{L}_{1}$ and $\mathrm{L}_{3}$ mark off the coal pillar structure and $\mathrm{L}_{2}$ is 
the center line. The vertical displacement of coal pillar structure displays an increasing trend from point $\mathrm{E}$ in the floor to the roof. Function fitting is conducted to the vertical displacement of coal pillar structure and the trend of displacement function is shown in Figure 12.

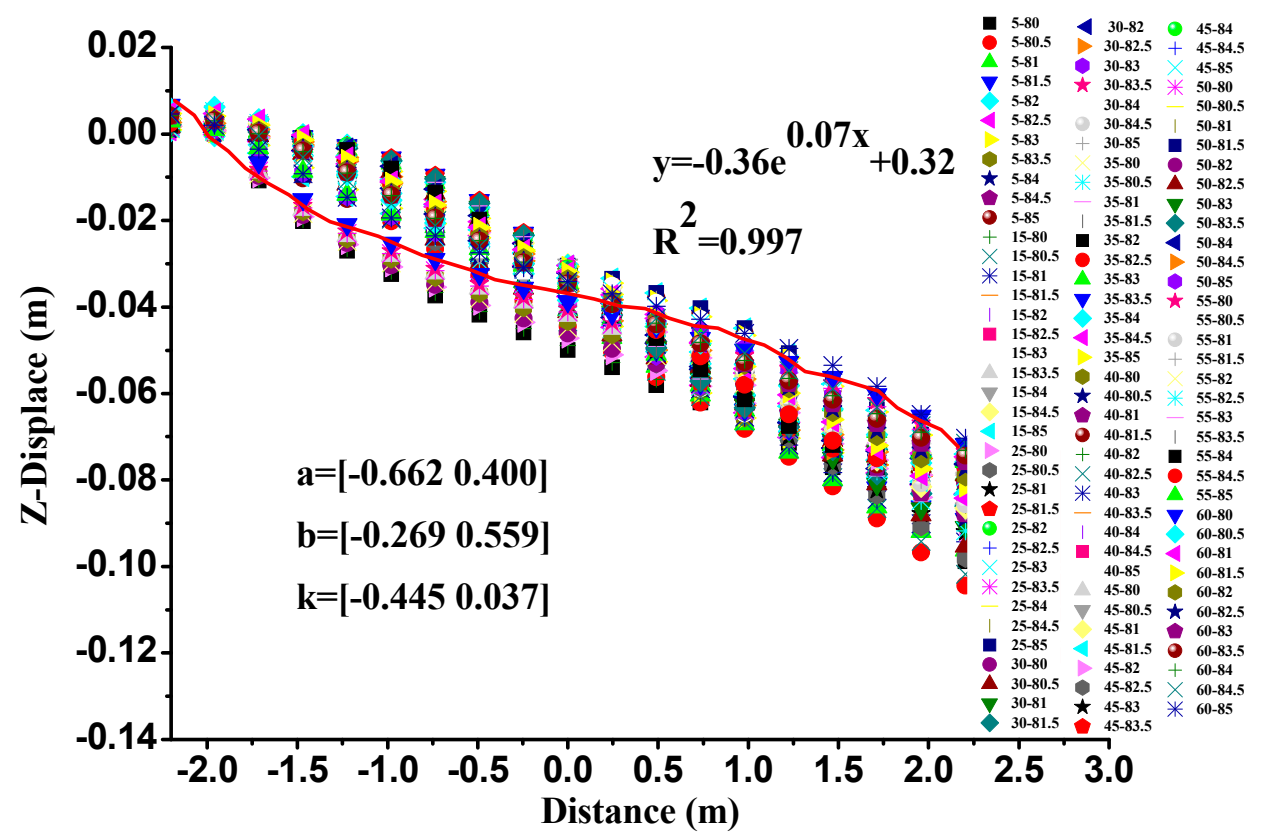

Figure 12. Fitting function diagram of vertical displacement.

Through data processing and function fitting of the changing trend of Z-displacement, it can be concluded that the relationship between Z-displacement and coal pillar structure at different driving distances is in line with the growth trend of exponential function. The basic form of its exponential equation is as follows: $y=k^{a x}+b$. And the value range of parameter $a$ is $[-0.662,0.400]$, that of $b$ is $[-0.269,0.559]$, and that of $k$ is $[-0.445,0.037]$.

From fitting function analysis and the statistics of vertical displacement, two conclusions can be drawn. One is that the maximum displacement of a coal pillar structure occurs near the roof; meanwhile due to the transmission between the roof and coal pillar structure, relatively large displacement occurs in the coal/rock mass above the roof. The other is that there exists a displacement difference in coal pillar structure FG; the displacement difference increases from Point $\mathrm{E}$ to the roof and reaches a noticeable degree near the roof, which indicates that the displacement derivation near the roof is the largest. This can be justified as the consequent of compression and shear failure under the stress of immediate roof. From the above analysis it can be drawn that there exists a dangerous zone of compression and shear failure which is composed of the control points of compression and shear failure inside coal pillar structure.

To sum up, the statistical analysis of horizontal and vertical displacement shows that there are two dangerous zones in coal pillar structure. The first one, mainly caused by tensile failure, is located inside coal pillar structure within the range of $2 \mathrm{~m}$ close to the roadway side. The second one, mainly caused by compression and shear failure due to unequal displacement derivation, is located near the roof.

\section{Field Practice of Gob-Side Entry Driving}

\subsection{Engineering Geological Conditions}

Shilawusu mine, which produces 10 million tons of coal a year, is located in Ordos City, Inner Mongolia, China [30]. The designed interval between coal seam $2-2_{\text {up }}$ and $2-2_{\mathrm{mid}}$ is $20.5-31.2 \mathrm{~m}$. With its Protodyakonov coefficient (f) being approximately 1.79, the coal seam is a soft -medium hard one. 
The layout of $221_{\text {up }} 01$ working face is shown in Figure 13. The average thickness of coal seam is $4.99 \mathrm{~m}$, and the dip angle is $0-4^{\circ}$, with an average burial depth of $700 \mathrm{~m}$. The roof is middle-fine sandstone (with an average thickness of $13.78 \mathrm{~m}$ ); the floor is sandy mudstone (with an average thickness of $2.67 \mathrm{~m}$ ). The overview of the roof and floor of coal seam is shown in Table 1. The length of gob-side entry driving is approximately $1000 \mathrm{~m}$, with relatively weak roof draining.

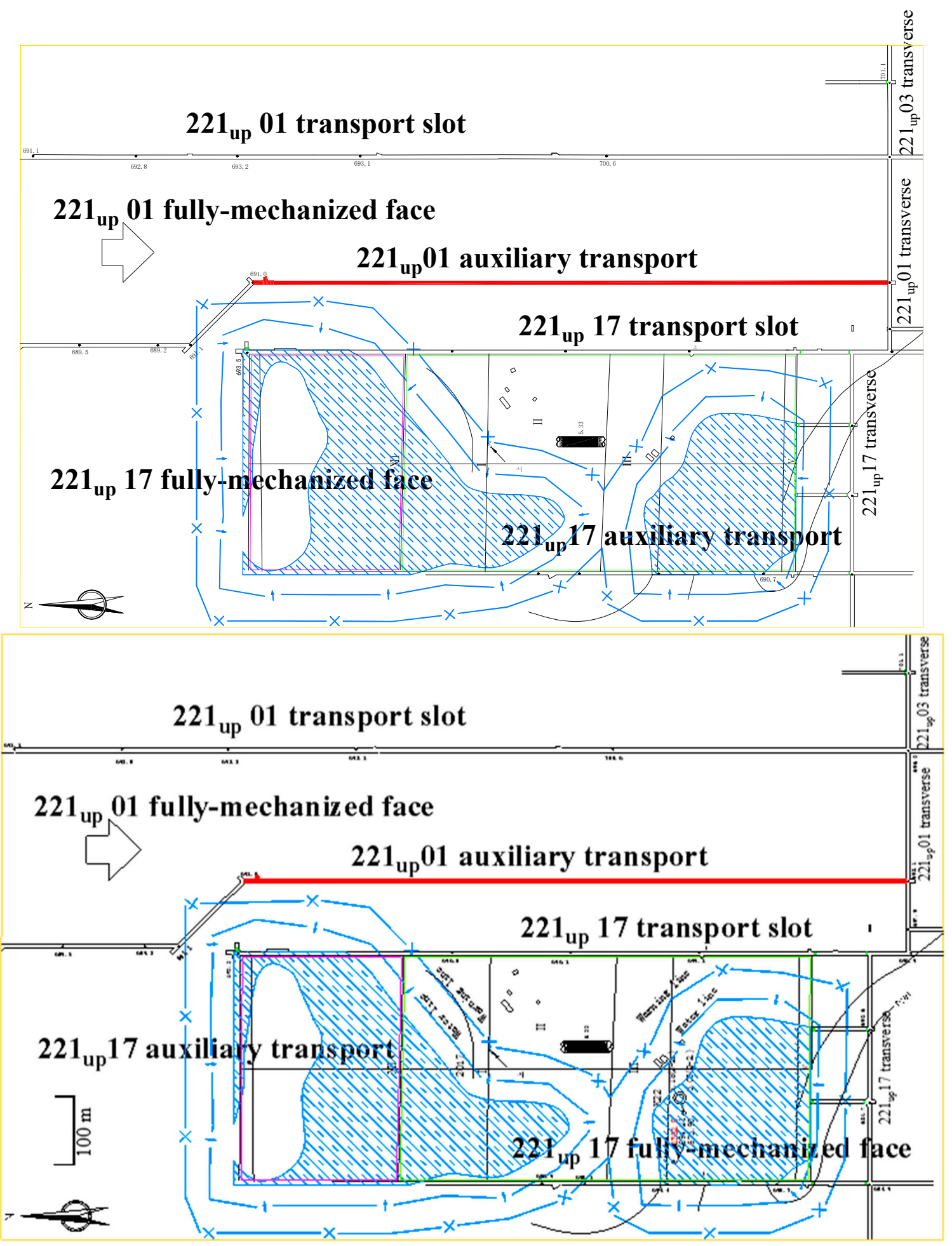

Figure 13. The layout of $221_{\mathrm{up}} 01$ working face. 
Table 1. The overview of the roof and floor of coal seam.

\begin{tabular}{ccc}
\hline Thickness $(\mathbf{m})$ & Lithology & Remarks \\
\hline 6.22 & Sandy mudstone & \\
0.42 & 2-1 Coal seam & \\
3.06 & Sandy mudstone & \\
13.78 & Middle-fine sandstone & Roof \\
4.99 & 2-2 Up Coal seam & Primary mineable coal bed \\
2.67 & Sandy mudstone & Floor \\
17.54 & Middle-fine sandstone & \\
\hline
\end{tabular}

\subsection{Field Support Conditions}

According to the field condition, the support of roadway driving along the gob can be divided into three different segments: general integral-support segment, key reinforced segment, and special-structured segment. The parameters of general integral-support are as follows: the roof is supported by seven $\Phi 22 \times 3000 \mathrm{~mm}$ high strength pre-tightening bolts, three $\Phi 21.8 \times$ $6100 \mathrm{~mm}$ steel-stranded high strength pre-tightening anchor cables, T-shape steel belts and bar-mat reinforcement for surface protection. The bolt array pitch is $800 \times 800 \mathrm{~mm}$ and the cables are arranged in "3-0-3" way with the array pitch being $1600 \times 1200 \mathrm{~mm}$. The pre-tightening force on the cable should be no smaller than $250 \mathrm{~N} / \mathrm{m}$ and that of cable should be no smaller than $200 \mathrm{kN}$. The coal pillar side is supported by five $\Phi 20 \times 2200 \mathrm{~mm}$ high strength pre-tightening bolts and 10\# wire meshes plus steel ladder beam for surface protection. The bolt array pitch is $800 \times 800 \mathrm{~mm}$. The mining side is supported by five $\Phi 20 \times 2200 \mathrm{~mm}$ FRP bolts at an array pitch of $800 \times 800 \mathrm{~mm}$ and mine double-resistant plastic net plus GT10/4300 steel ladder beam for surface protection. Besides, the bolts at the shoulder position are operated at an angle of $15^{\circ}$ with the horizontal plane while other bolts are operated vertical to the plane.

\subsection{Field Measurement and Effect Analysis}

In the process of gob-side entry driving, the load of bolts and cables was monitored to supervise the stability of the coal pillar structure. Meanwhile, by means of the images obtained from a pillar-side borehole peep, the comprehensive characteristics of the coal pillar structure in the driving process were analyzed. Figure 14 shows the monitoring site distribution of bolt and cable load. UROICA MCS-400 Bolt (Cable) force measuring system was used to monitor and analyze the load. The relationship between bolt and cable load and driving distance is shown in Figure 15.

The monitoring station was set at the driving distance of $962 \mathrm{~m}$ and had five monitoring sites in total. 1\# monitoring site was located at the bolt end of coal pillar side, 2\# and 4\# monitoring sites were set at the bolt end of the roof, $3 \#$ monitoring site was set at the cable end of the roof, and $5 \#$ monitoring site was set at bolt end of mining side.

As it is shown in Figure 15, the readings of bolt (anchor cable) dynamometers indicate that there are two sections of load change. The first section is the initial impact section. During this period, the head-on working face advances continuously and the dynamometers are under the impact of roof and rib displacements. As can be seen, the bolt (anchor cable) load increases quickly. The second section is the stable expansion section with bolt (anchor cable) load increasing slowly or keeping stable. 


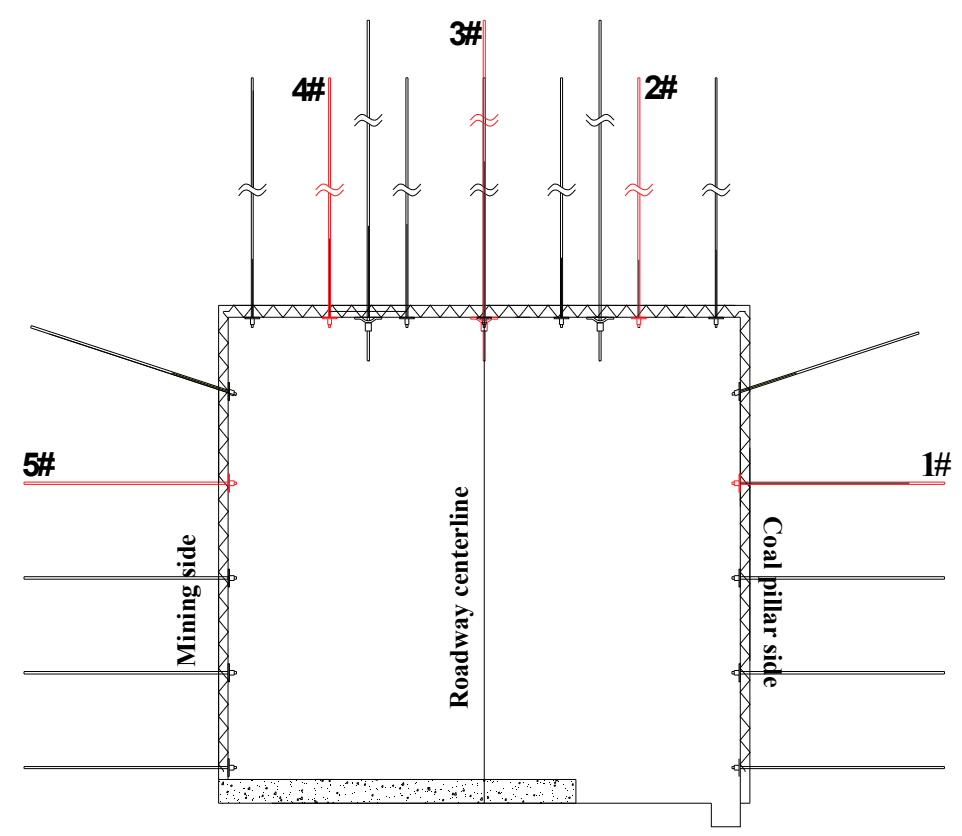

Figure 14. The monitoring site distribution of bolt (cable) load.

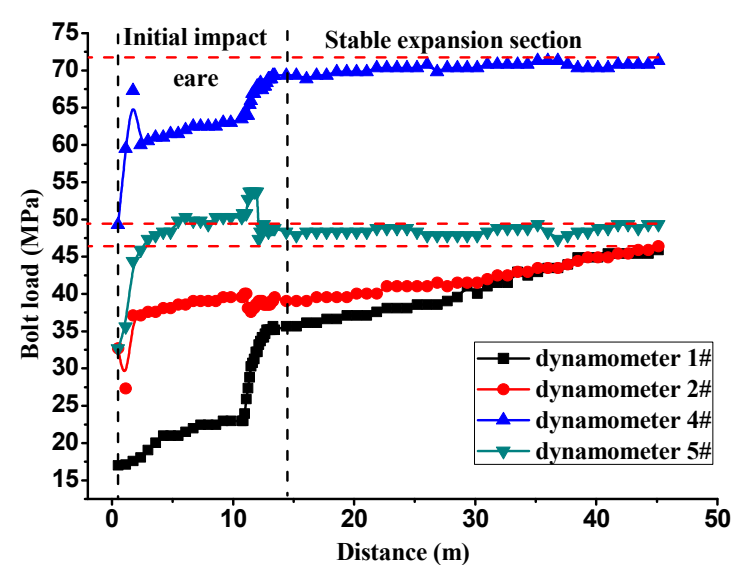

(a)

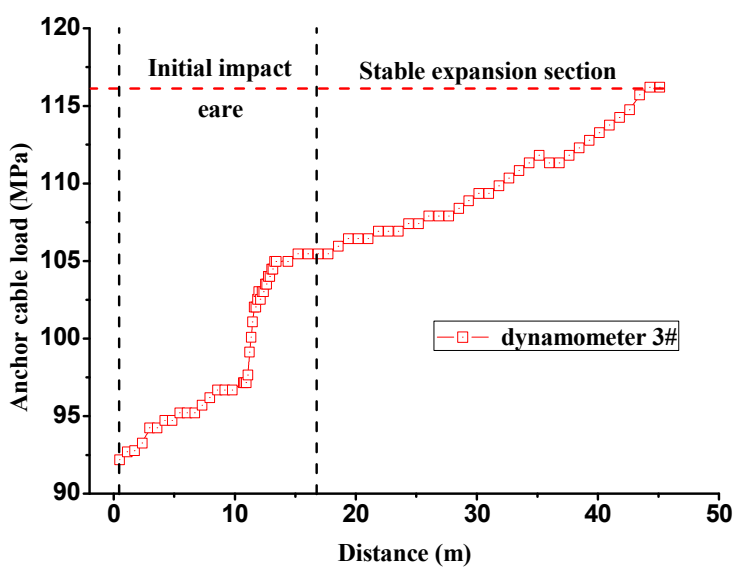

(b)

Figure 15. The relationship between bolt (anchor cable) load and the distance to the head-on. (a) The relationship between bolt load and the distance to the head-on; (b) The relationship between anchor cable load and the distance to the head-on.

As is indicated in Figure 15, the initial bolt load on the ribs reaches $17 \mathrm{MPa}$, that on the roof reaches $28 \mathrm{MPa}$ and the initial cable load on the roof reaches $93 \mathrm{MPa}$. This can be taken as an indicator of meeting the demand of "high pre-tightening force and strong anchorage" raised by the support parameters. On this basis, the characteristics of coal pillar stability are analyzed with the images obtained from borehole peep. Figure 16 shows the control points of borehole peep.

According to the design requirements, the angle and depth of the borehole peep at the coal pillar side should be $45^{\circ}$ and $60^{\circ}$, and $18 \mathrm{~m}$ and $21 \mathrm{~m}$, respectively; the borehole peep on the roof should be vertical with a depth of $15 \mathrm{~m}$. However, the maximum drilling depth of the drilling equipment available in the working face is only $10 \mathrm{~m}$. Consequently, the borehole depth in this study is $10 \mathrm{~m}$. The borehole peep images are shown in Figure 17. 


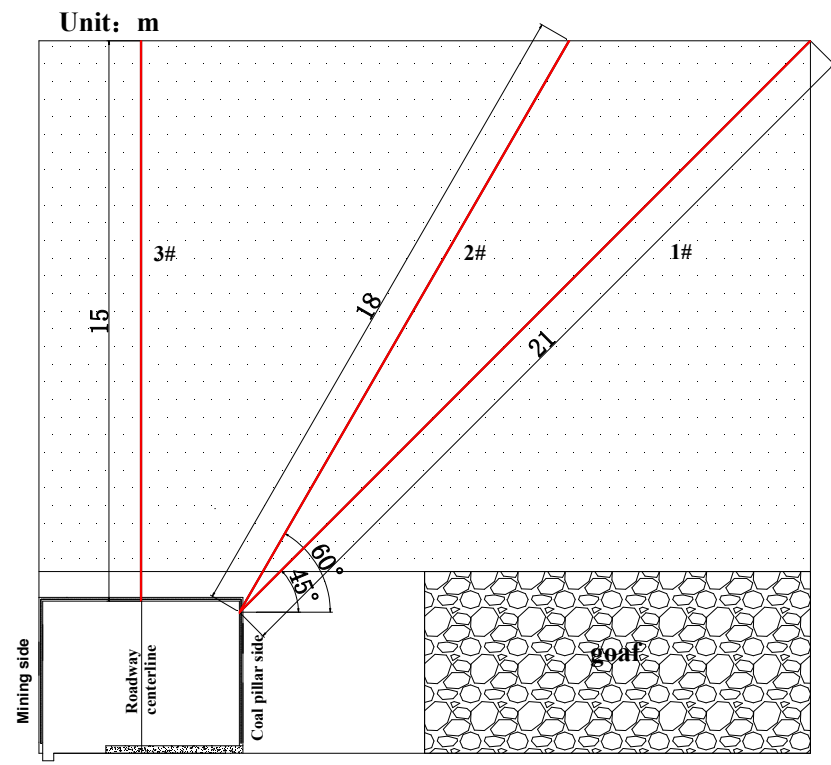

Figure 16. The control point distribution of borehole peep.

According to the analysis of borehole peep images and given that the drilling at the coal pillar side is at certain angles, the actual fracture development zone revealed by $1 \#$ and $2 \#$ boreholes can be calculated out and shown in Table 2.

Table 2. An overview of fracture development zone.

\begin{tabular}{cccc}
\hline Borehole Number & $\begin{array}{c}\text { Fracture Development } \\
\text { Zone }(\mathbf{m})\end{array}$ & $\begin{array}{c}\text { The Depth into Coal } \\
\text { Pillar Side (m) }\end{array}$ & $\begin{array}{c}\text { The Depth into the } \\
\text { Roof }(\mathbf{m})\end{array}$ \\
\hline \multirow{2}{*}{$1 \#$} & $3.1-3.3$ & $2.19-2.33$ & $2.19-2.33$ \\
& $4.5-4.7$ & $3.18-3.32$ & $3.18-3.32$ \\
$5.2-5.5$ & $3.68-3.89$ & $3.68-3.89$ \\
\hline \multirow{2}{*}{ 2\# } & $2.1-2.3$ & $1.05-1.15$ & $1.82-1.99$ \\
& $4.9-5.2$ & $2.45-2.60$ & $4.24-4.50$ \\
& $5.2-5.5$ & $2.60-2.75$ & $4.50-4.76$ \\
& $5.5-5.9$ & $2.75-2.95$ & $4.76-5.11$ \\
\hline
\end{tabular}

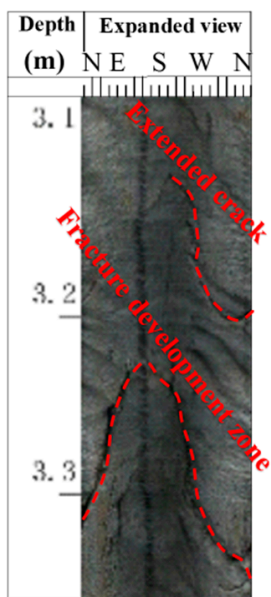

(a)

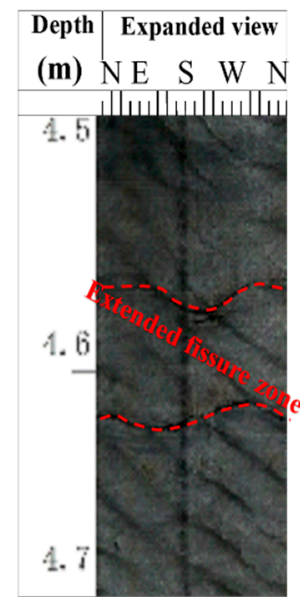

(b)

Figure 17. Cont. 


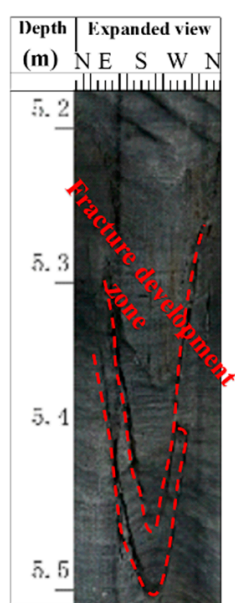

(c)

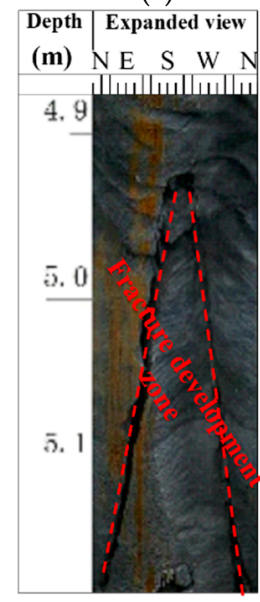

(e)

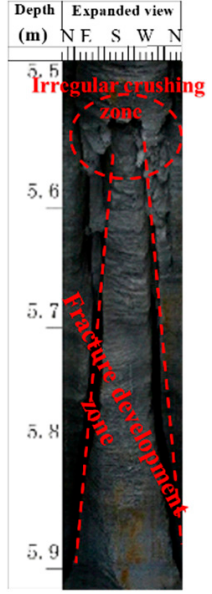

(g)

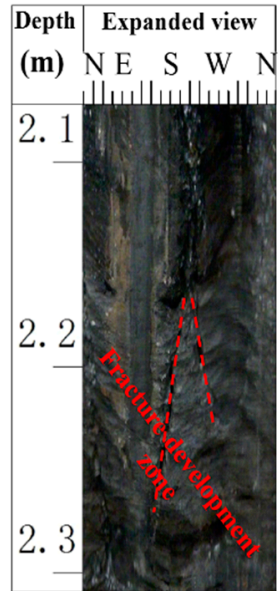

(d)

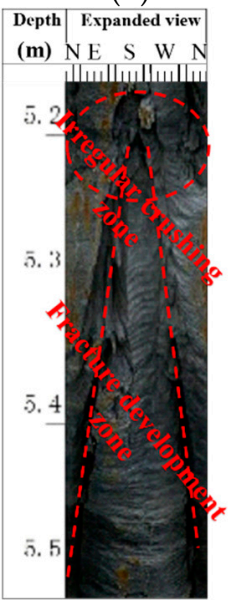

(f)

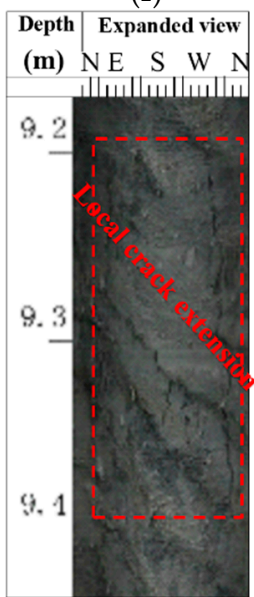

(h)

Figure 17. Borehole peep images. (a) coal pillar side $45^{\circ} 1$ \# borehole image at the depth of 3.1-3.3 m; (b) coal pillar side $45^{\circ} 1$ \# borehole image at the depth of $4.5-4.7 \mathrm{~m}$; (c) coal pillar side $45^{\circ} 1$ \# borehole image at the depth of 5.2-5.5 m; (d) coal pillar side $60^{\circ}$ 2\# borehole image at the depth of 2.1-2.3 m; (e) coal pillar side $60^{\circ} 2 \#$ borehole image at the depth of $4.9-5.2 \mathrm{~m}$; (f) coal pillar side $60^{\circ} 2 \#$ borehole image at the depth of 5.2-5.5 m; (g) coal pillar side $60^{\circ}$ 2\# borehole image at the depth of 5.5-5.9 m; (h) roof $90^{\circ} 3 \#$ borehole image at the depth of $9.2-9.4 \mathrm{~m}$.

Through the statistics of fracture development zone, the borehole fracture imaging model can be drawn and shown in Figure 18. As can be seen, the drilling depth is $10 \mathrm{~m}$ and two fracture development zones (demoted as $\mathrm{Q}$ and $\mathrm{S}$, respectively) appear within the range of 2-5 $\mathrm{m}$ above the 
coal pillar. In zone $\mathrm{Q}$ (shallow zone), the fracture development is still in an early stage and the fractures are mainly extended cracks and fissures; comprehensively speaking the degree of damage is relatively low. In zone S (deep zone), the fracture development is virtually complete and the degree of damage is correspondingly higher. Zone $S$ is closer to the goaf and therefore the sinking torque force from the key blocks of overlying strata is more remarkably transmitted. As a result, a V-shape fracture can be seen from the borehole peep images and the damage is also clear. As is stated above, the fracture development in zone $Q$ is still in an early stage and therefore displays a "- "-shape extension under the stress transmitted from overlying strata. Meanwhile, the brittle characteristics and joint development of the coal/rock mass also play a certain role in this process. The borehole peep image from the roof shows that all the segments are relatively smooth except the segment of 9.2-9.4 $\mathrm{m}$ where micro-fissures appear.

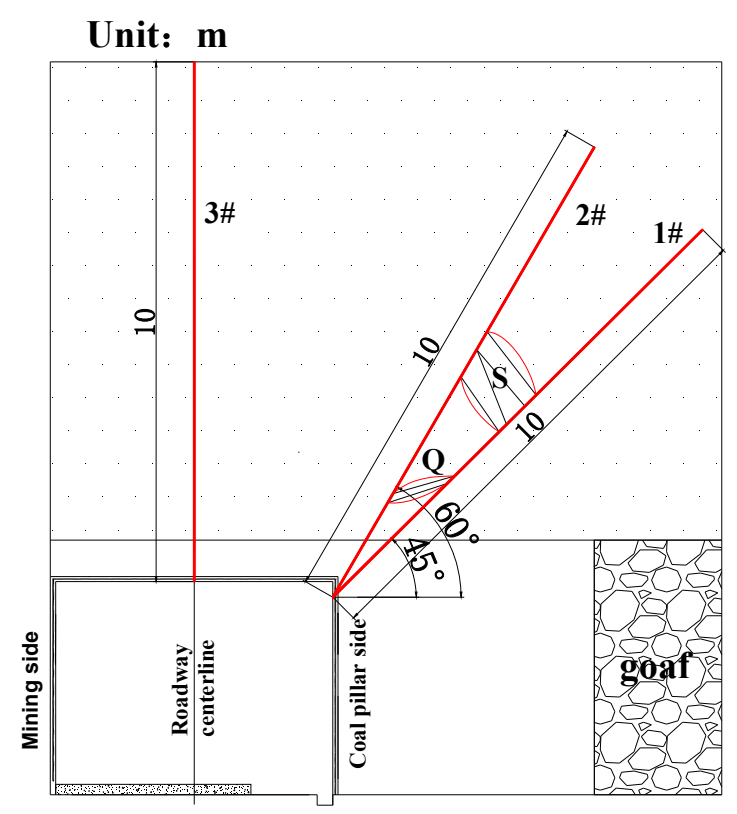

Figure 18. The diagram of borehole fracture imaging model.

As is shown by the borehole peep images, there exists an inverted V-shape fracture zone within the range of 3-5 m deep into coal pillar and above the goaf. Once exceeding the range, the images show that rock mass is relatively smooth. Given that the fracture development is not complete in zone $\mathrm{Q}$ and the roof displays a good integrity, it can be deduced that coal pillar structure has been impacted by the torque force transmitted from overlying strata and certain damage has been caused upon the roof strata close the goaf (the inverted V-shape fracture zone is a convincing indicator). However, as a whole the roadway displays a relatively high smoothness and there is no bed separation or fracture surface. Therefore it can be inferred that the overall coal pillar structure is highly stable.

\section{Conclusions}

(1) A numerical model of coal pillar structure is established by constructing the key roof blocks of narrow coal pillar in the process of gob-side entry driving. Through analyzing the apparent steady state of the model established, it can be concluded that there exists a group of shear forces. Due to the heterogeneous transmission of overlying strata, the integrated shear force is located closer to the goaf side. Meanwhile, the strength of the integrated shear force is mainly related with the fracture length of key blocks of overlying strata and the joint development state inside coal pillars. Under the action of the integrated shear force, displacements occur in opposite directions inside the coal pillar structure. All the displacement control points, when connected, constitute a concave surface inside the coal pillar. The curve formed in the plane vertical to the 
axis of the coal pillar is called the "instability critical line". This critical line is also the area where displacement is most likely to occur and thus instability and failure are occurrence of the highest probability inside the coal pillar structure.

(2) A three-dimensional stress structure model of gob-side entry driving is established, through which the law of stress peak values in different zones is obtained. To be specific, the stress peak value of the head-on stress disturbance zone is larger than that of the stress distribution zone at the solid coal side, while the latter is larger than that of stress distribution zone in a coal pillar structure. The stress distribution of the stress core area inside a coal pillar structure displays a trend of steady growth and drastic decline. The discontinuity point of peak value in the stress core area is located close to the roadway, and the starting point of the stress core area is close to the gob-side. From the starting point to the discontinuity point, the stress grows steadily; but it falls dramatically after the discontinuity point. In addition, the stress core area is located close to the roadway side as a whole. As the driving distance is over $40 \mathrm{~m}$, the stress distribution of coal pillar structure appears to be tooth-like.

(3) In the loading process, two dangerous zones appear in coal pillar structure. One is due to tensile failure and the other is due to compression/shear failure. The control points of tensile failure constitute a concave surface and form an "instability critical line" in the plane vertical to the axis of the coal pillar structure, which is in line with the calculation results of the coal pillar mechanical structure model. The corresponding structural form is as follows: the control point on the roof is closer to the roadway while that on the floor is located within the range of 1.4-2 $\mathrm{m}$ deep inside the coal pillar structure. The dangerous zone caused by compression/shear failure is close to the roof of the coal pillar.

(4) Based on the results of bolt (anchor cable) load monitoring and borehole peep imaging at the coal pillar side, the effects of support parameters for "high pre-tightening force and strong anchorage" in the working face of gob-side entry driving are evaluated. The monitoring results indicate that the rock mass layer of a coal pillar structure is highly smooth with a relatively stable loading effect. A whole set of efficient, hence sustainable, utilization technology for coal pillars are formed accordingly.

Author Contributions: Data curation, X.L.; Formal analysis, X.L., Z.X., and D.L.; Funding acquisition, N.Z.; Investigation, X.L.; Project administration, N.Z. and Y.Z.; Software, X.L.; Writing-original draft, X.L.; Writing-review and editing, X.L., N.Z., and Z.X.

Funding: This work was financially supported by the Fundamental Research Funds for the Central Universities (2017CXNL01).

Acknowledgments: The authors are grateful to the staff at the Shilawusu Coal Mine for their assistance during the field measurements.

Conflicts of Interest: The authors declare no conflict of interest.

\section{Abbreviations}

$\mathrm{M}_{0} \quad$ beam section internal force at the starting point before the fracture of main roof

$\mathrm{M}_{\mathrm{x}} \quad$ maximum bending moment before the fracture of main roof

F supporting force on main roof

Q weight and load of fractured strata

$\mathrm{N}$ horizontal force caused by the rotation of fractured rock structure

E elasticity modulus of main roof

$\mathrm{R}_{\mathrm{S}} \quad$ tensile strength of main roof

$\mathrm{h}$ thickness of main roof

b width of main roof

$\gamma \quad$ unit weight of main roof strata

k cushion coefficient 
q load intensity on the overhanging part of fractured rock

$\Delta S \quad$ vertical displacement difference between the two ends of fractured rock

$\mathrm{L} \quad$ length of fractured rock in main roof

$\mathrm{F}_{Y} \quad$ regional stress transmitted from the roof

$\mathrm{F}_{\mathrm{Z}} \quad$ regional stress transmitted from the floor

$\mathrm{F}_{\mathrm{G}} \quad$ regional stress of coal pillar anchorage zone

$\mathrm{F}_{\mathrm{M}} \quad$ stress transmitted from coal pillar friction

$\mathrm{c}_{1} \quad$ rotation coefficient of the coal pillar structure

$\mathrm{c}_{2} \quad$ horizontal deviation coefficient of the coal pillar structure

$\mathrm{c}_{3} \quad$ vertical deviation coefficient of the coal pillar structure

\section{References}

1. Gao, W.; Ge, M. Stability of a coal pillar for strip mining based on an elastic-plastic analysis. Int. J. Rock Mech. Min. Sci. 2016, 87, 23-28. [CrossRef]

2. Chen, S.J.; Guo, W.J.; Zhou, H.; Shen, B.T.; Liu, J.B. Field investigation of long-term bearing capacity of strip coal pillars. Int. J. Rock Mech. Min. Sci. 2014, 70, 109-114. [CrossRef]

3. Zhou, Z.; Chen, L.; Cai, X.; Shen, B.T.; Zhou, J.; Kun, D. Experimental Investigation of the Progressive Failure of Multiple Pillar-Roof System. Rock Mech. Rock Eng. 2018, 51, 1629-1636. [CrossRef]

4. Guo, W.; Wang, H.; Chen, S. Coal pillar safety and surface deformation characteristics of wide strip pillar mining in deep mine. Arab. J. Geosci. 2016, 9, 137. [CrossRef]

5. Chen, S.J.; Yin, D.W.; Zhang, B.L.; Ma, H.F.; Liu, X.Q. Mechanical characteristics and progressive failure mechanism of roof-coal pillar structure. Chin. J. Rock Mech. Eng. 2017, 7, 1588-1598.

6. Chen, S.J.; Zhou, H.; Guo, W.J.; Wang, H.L.; Sun, X.Z. Study on Long-Term Stress and Deformation Characteristics of Strip Pillar. J. Min. Saf. Eng. 2012, 29, 376-380.

7. Zhou, A.; Wang, K.; Li, L.; Wang, C. A roadway driving technique for preventing coal and gas outbursts in deep coal mines. Environ. Earth Sci. 2017, 76, 236. [CrossRef]

8. Yang, H.; Cao, S.; Wang, S.; Fan, Y.; Wang, S.; Chen, X. Adaptation assessment of gob-side entry retaining based on geological factors. Eng. Geol. 2016, 209, 143-151. [CrossRef]

9. Bai, Q.; Tu, S.; Wang, F.; Zhang, C. Field and numerical investigations of gateroad system failure induced by hard roofs in a longwall top coal caving face. Int. J. Coal Geol. 2017, 173, 176-199. [CrossRef]

10. Han, C.L.; Zhang, N.; Xue, J.H.; Kan, J.G.; Zhao, Y.M. Multiple and Long-Term Disturbance of Gob-Side Entry Retaining by Grouped Roof Collapse and an Innovative Adaptive Technology. Rock Mech. Rock Eng. 2018, 1-13. [CrossRef]

11. Zhang, M.; Jiang, F.X.; Li, J.Z.; Jiao, Z.H.; Hu, H.; Shu, C.X.; Gao, H.J. Stability of coal pillar on the basis of the co-deformation of thick rock strata and coal pillar. Rock Soil Mech. 2018, 39, 705-714.

12. Zhang, M.; Jiang, F.X.; Li, K.Q.; Wang, C.; Wu, X.; Gao, H.; Ji, S. Study of the compatible deformation and stability of the system of super thick strata and coal pillars. Chin. J. Rock Mech. Eng. 2017, 36, 326-334.

13. Zhang, H.; Wan, Z.; Ma, Z.; Zhang, Y. Stability control of narrow coal pillars in gob-side entry driving for the LTCC with unstable overlying strata: A case study. Arab. J. Geosci. 2018, 11, 665. [CrossRef]

14. Zha, W.; Shi, H.; Liu, S.; Kang, C. Surrounding rock control of gob-side entry driving with narrow coal pillar and roadway side sealing technology in Yangliu Coal Mine. Int. J. Min. Sci. Technol. 2017, 27, 819-823. [CrossRef]

15. Jiang, L.S.; Zhang, P.P.; Chen, L.J.; Hao, Z.; Sainoki, A.; Mitri, H.S.; Wang, Q.B. Numerical approach for goaf-side entry layout and yield pillar design in fractured ground conditions. Rock Mech. Rock Eng. 2017, 50, 3049-3071. [CrossRef]

16. Yao, Q.L.; Li, X.H.; Sun, B.Y.; Ju, M.H.; Chen, T.; Zhou, J.; Liang, S.; Qu, Q.D. Numerical investigation of the effects of coal seam dip angle on coal wall stability. Int. J. Rock Mech. Min. Sci. 2017, 12, 298-309. [CrossRef]

17. Sun, W.; Zhang, Q.; Luan, Y.Z.; Zhang, X.P. A study of surface subsidence and coal pillar safety for strip mining in a deep mine. Environ. Earth Sci. 2018, 77, 5-16. [CrossRef]

18. Zhou, Z.; Chen, L.; Zhao, Y.; Zhao, T.; Cai, X.; Du, X. Experimental and Numerical Investigation on the Bearing and Failure Mechanism of Multiple Pillars Under Overburden. Rock Mech. Rock Eng. 2017, 50, 995-1010. [CrossRef] 
19. Rafiei Renani, H.; Martin, C.D. Modeling the progressive failure of hard rock pillars. Tunn. Undergr. Space Technol. 2018, 74, 71-81. [CrossRef]

20. He, Y.Y.; Song, X.M.; Zhao, J.C. A study on damage proneness of coal pillars of different sizes under complicated compression conditions. J. Min. Saf. Eng. 2015, 4, 592-596.

21. Zhang, X.G.; Yao, Z.G.; Zhang, N. Stress Distribution of Coal Pillar with Gob-Side Entry Driving in the Process of Excavation \& Mining. J. Min. Saf. Eng. 2012, 4, 459-465.

22. Zheng, X.G.; An, T.L.; Guo, Y. Surrounding rock control mechanism and engineering application of in-situ coal pillar in gob-side entry retaining. J. Min. Saf. Eng. 2018, 6, 1091-1098.

23. Zhao, G.Z.; Ma, Z.G.; Sun, K.; Fan, J.Q.; Li, K. Research on Deformation Controlling Mechanism of the Narrow Pillar of Roadw ay Driving A long Next Goaf. J. Min. Safe Eng. 2010, 4, 517-521.

24. Kumar, A.; Waclawik, P.; Singh, R. Performance of a coal pillar at deeper cover: Field and simulation studies. Int. J. Rock Mech. Min. Sci. 2019, 113, 322-332. [CrossRef]

25. Mathey, M.; van der Merwe, J.N. Critique of the South African squat coal pillar strength formula. J. South. Afr. Inst. Min. Metall. 2016, 116, 291-299. [CrossRef]

26. Xi, J.M.; Mao, J.H.; Yang, G.S.; Wang, J.F. Method for Determining Rational Pillar Width in Mining Roadway Along Goaf. J. Min. Saf. Eng. 2008, 4, 400-403.

27. Qian, M.G.; Zhao, G.J. The Influence of the Fracture of the Main Roof on the Mining Ground Pressure. J. China Univ. Min. Technol. 1986, 4, 14-22.

28. Zhang, T.C. Analysis of Influencing Factors and Control on Driving Speed of Coal Roadway in Hulu Su Coal Mine. Available online: http:/ / kreader.cnki.net/Kreader/CatalogViewPage.aspx?dbCode=cdmd\& filename=1017950300.nh\&tablename=CMFD201801\&compose $=\&$ first $=1 \& u i d=($ accessed on 21 March 2019).

29. Hou, C.J.; Ma, N.J. Stress in In-seam Roadway Sides and Limit Equilibrium Zone. J. China Coal Soc. 1989, 4, 21-29.

30. Xie, P. Predictions of Height of Water Flowing Fractured Zone and Water Inflow under Fully Mechanized Top-Coal Caving of Shilawusu Coal Mine. Available online: http://kreader.cnki.net/Kreader/ CatalogViewPage.aspx?dbCode $=$ cdmd\&filename=1018827078.nh\&tablename=CMFD201802\&compose $=$ \&first=1\&uid= (accessed on 21 March 2019).

31. Kim, B.; Walton, G.; Larson, M.K.; Berry, S. Experimental study on the confinement-dependent characteristics of a Utah coal considering the anisotropy by cleats. Int. J. Rock Mech. Min. Sci. 2018, 105, 182-191. [CrossRef] 